SYNERGISTIC CISPLATIN-INDUCED CELL DEATH BY ULTRASOUNDMICROBUBBLE MEDIATED INTRACELLULAR DELIVERY IN BREAST

CANCER CELLS

\author{
by \\ Sheliza Jetha \\ B.Sc. University of Waterloo, 2012 \\ Toronto, Canada
}

\begin{abstract}
A thesis
presented to Ryerson University

in partial fulfillment of the

requirements for the degree of

Master of Science

in the Program of Biomedical Physics
\end{abstract}

Toronto, Ontario, Canada, 2016

(C) Sheliza Jetha, 2016 


\section{Author's Declaration}

I hereby declare that I am the sole author of this thesis. This is a true copy of the thesis, including any required final revisions as accepted by my examiners.

I authorize Ryerson University to lend this thesis to other institutions or individuals for the purpose of scholarly research.

I further authorize Ryerson University to reproduce this thesis by photocopying or by other means, in total or in part, at the request of other institutions or individuals for the purpose of scholarly research.

I understand that my thesis may be made electronically available to the public.

Sheliza Jetha 


\title{
Abstract \\ Synergistic Cisplatin-induced cell death by ultrasound-microbubble mediated intracellular delivery in breast cancer cells
}

\author{
Sheliza Jetha \\ Master of Science, Biomedical Physics \\ Ryerson University, 2016.
}

Ultrasound-microbubble (USMB) potentiated cisplatin (CDDP) therapy was assessed in human breast cancer cells. Cells, MDA-MB-231, in suspension were exposed to USMB and CDDP at varying conditions, during which microbubble cavitation activity was measured using passive cavitation detection and 48 hours post-treatment cell viability and intracellular platinum concentration were measured using MTT assay and mass cytometry, respectively. USMB synergistically enhanced cell death ( 20 fold) when combined with CDDP and significantly increased intracellular CDDP concentration ( $\sim 8$ fold) compared to CDDP treatment alone. Cell death and intracellular CDDP concentration were correlated to microbubble cavitation activity, which increased with peak negative pressure and microbubble concentration. Combined treatment of USMB and CDDP at relatively lower integrated cavitation dose (ICD) induced a synergistic effect on cell death whereas ICD greater than 10 induced an additive effect. USMB mediated CDDP intracellular accumulation synergistically enhances cell death in CDDPresistant breast cancer cells. 


\section{Acknowledgements}

This work would not be possible without my supervisor, Dr. Karshafian. I would like to thank him for his patience, continuous support and tuteledge. I am truly grateful to have him as my mentor and for all the opportunities I was given.

I would like to thank my committee members Dr. Michael Kolios and Dr. Roberto Botelho for their advice and knowledge throughout my thesis to help prepare me for the completion of this degree. They both have also been very generous with the use their equipment and lab spaces.

Special thanks to all lab members of Dr. Karshafian's group for their encouragement and support over the years; notably to Shadab Momin for assisting me in microbubble activity experiments and analysis.

Last but not least I'd like to thank my family for supporting me and Shafqat Dattu for believing in me and standing by me through the high's and low's of this journey. 


\section{Table of Content}

Author's Declaration ............................................................................................................ ii

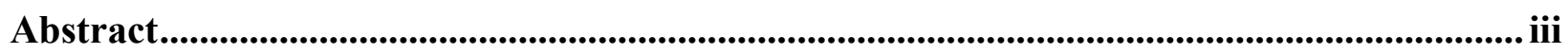

Acknowledgements ....................................................................................................................... iv

List of Tables .............................................................................................................................................. vii

List of Figures................................................................................................................ vii

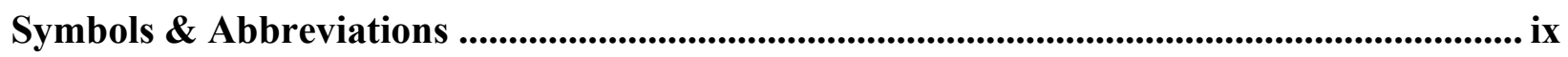

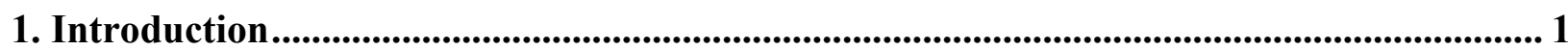

1.1 Background and Motivation .................................................................................................. 1

1.2 Cancer and Chemotherapy ……................................................................................................. 2

1.3 Platinum based chemotherapeutic agent cisplatin............................................................... 3

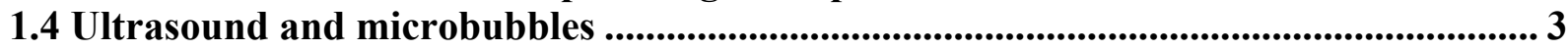

1.5 Chemotherapy and ultrasound-microbubbles ......................................................................... 5

1.6 Hypothesis and specific objectives........................................................................................... 9

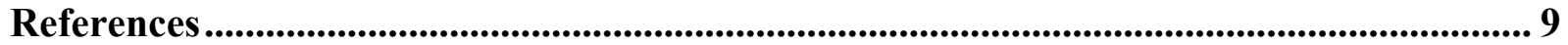

2. Synergistic Cisplatin-induced cell death by ultrasound-microbubble mediated intracellular delivery in breast cancer cells............................................................................... 13

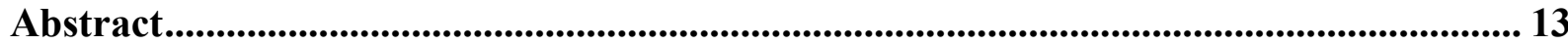

2.1 Introduction............................................................................................................................. 15

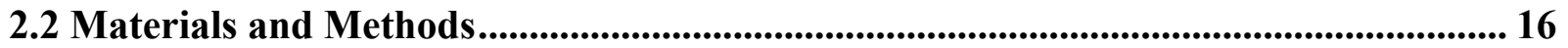

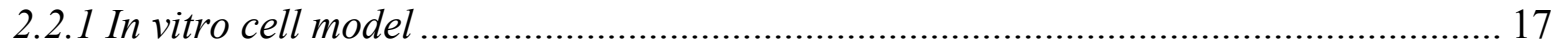

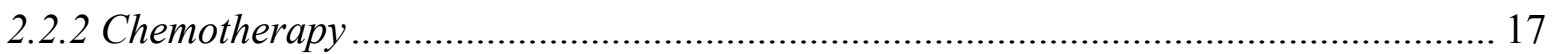

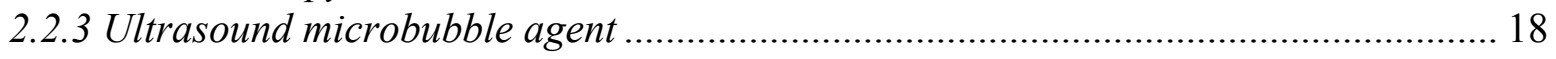

2.2.4 Ultrasound exposure system ................................................................................. 18

2.2.5 Cavitation Dose: Passive Cavitation Detection ......................................................... 19

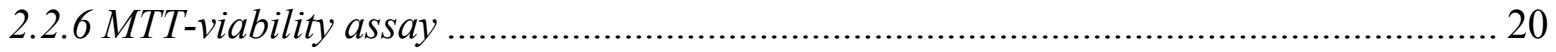

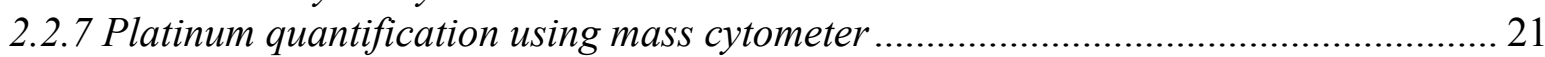

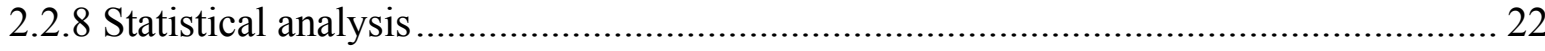

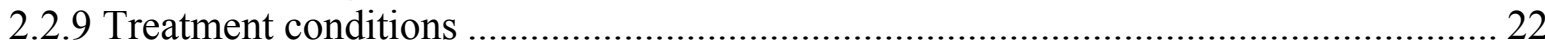

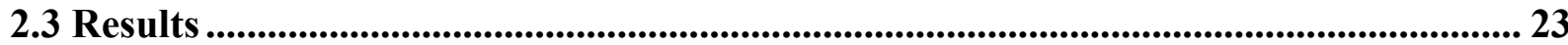

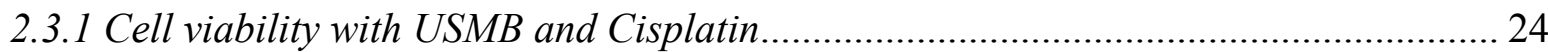

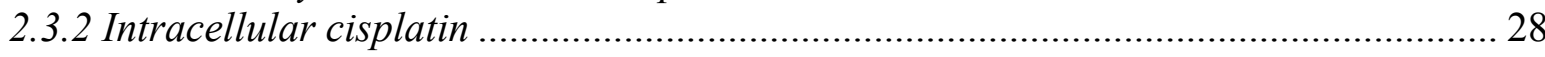

2.3.3 Integrated cavitation dose (ICD) ......................................................................... 29

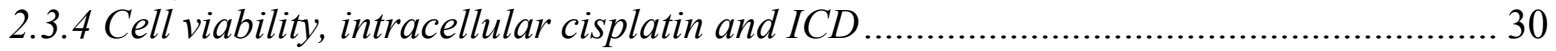

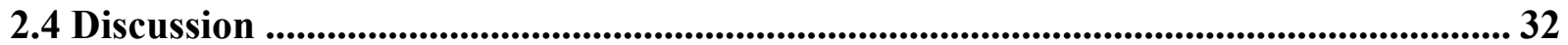

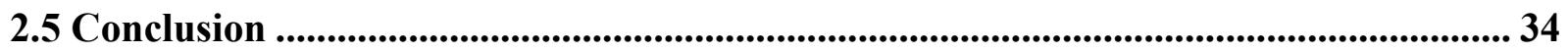

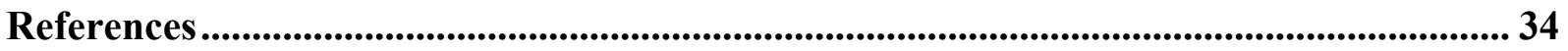

Supplementary information .............................................................................................................. 38

Intracellular platinum concentration per cell $(\mu M)$....................................................... 38

Cell viability comparison of statistically significant treatment conditions ......................... 39 


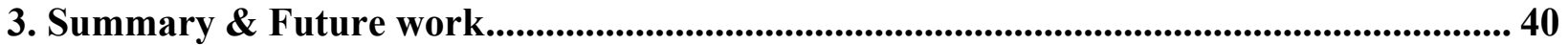

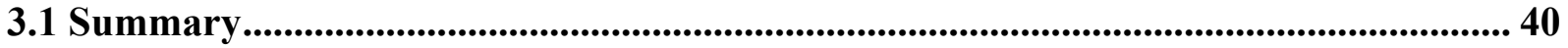

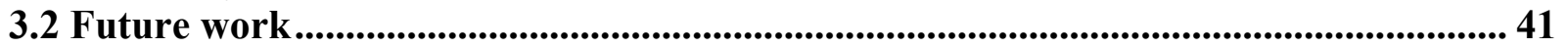




\section{List of Tables}

Table 1: Ultrasound peak negative pressures studied at each microbubble concentration

Table 2: Variables used to calculate intracellular cisplatin concentation obtained from either tuning solution or mass cytometer data gating using CytoBank 38

Table 3: Summary of non-parametric t-test comparison between CDDP alone and combined $U S M B+C D D P$ treatments, where * represents statistically significant conditions 39 


\section{List of Figures}

Figure 1: Schematics of (A) US exposure setup and (B) Passive Cavitation Detection setup. _ 20

Figure 2: Schematic diagram of treatment conditions for MTT assay viability experiments and mass cytomtery uptake measurements with USMB.

Figure 3: Percent cell viability of breast cancer cells for both CDDP alone and combinational treatments $C D D P+U S M B$ and $U S M B+15$ mins $+C D D P$.

Figure 4: Comparison between expected additive cell viability and experimental cell viability for each treatment condition in the presence of CDDP and USMB for both treatment orders.

Figure 5: Quantified intracellular CDDP concentration for $3 \mu M C D D P$ concentration with or without USMB.

Figure 6: Integrated cavitation dose of the second harmonic frequency.

Figure 7: (a) Cell viability correlated with intracellular platinum concentration; (b) The correlation between cell viability and second harmonic ICD; and (c) Correlation between intracellular CDDP concentration and second harmonics ICD. 


\section{Symbols \& Abbreviations}

$\begin{array}{ll}\text { USMB } & \text { Ultrasound and microbubble } \\ \text { MB(s) } & \text { Microbubble(s) } \\ \text { ICD } & \text { Integrated cavitation dose } \\ \text { Dox } & \text { Doxorubicin } \\ \text { CDDP } & \text { Cisplatin } \\ \text { BLM } & \text { Bleomycin } \\ \text { MCTX } & \text { Metronomic Cyclophosphamide } \\ \text { Top } & \text { Topotecan } \\ \text { CTR1 } & \text { Copper transporter 1 } \\ \text { ICP } & \text { Inductive Coupling Plasma } \\ \text { SEM } & \text { Standard error of the mean } \\ \text { Pneg } & \text { Peak negative pressure } \\ \text { CD } & \text { Cavitation dose }\end{array}$




\section{Introduction}

\subsection{Background and Motivation}

Efficacy of cisplatin depends on drug concentration and cancer type [1]. In cancers such as bladder, head, neck, ovarian, colorectal, lung and testicular, cisplatin triggers apoptosis by inducing DNA damages [2-4]; whereas in breast cancer, cisplatin seldom triggers apoptosis due to drug resistance. Insufficient DNA binding of cisplatin or the activation of anti-apoptotic pathways can induce drug resistance despite the presence of DNA damage $[2,5]$. Increasing intracellular cisplatin accumulation can increase DNA binding improving cisplatin efficacy [3, 6]. Various methods such as ultrasound-microbubble enhanced drug delivery, down-regulation of Bcl-2 expression, sonodynamic therapy, and combinational drug therapy, are being investigated in improving Cisplatin efficacy [2, 7-10]. This study investigates the possibility of using ultrasound-microbubble therapy in combination with cisplatin to enhance effectiveness in killing breast cancer cells by increasing intracellular cisplatin accumulation. Ultrasound-microbubble therapy has previously demonstrated enhanced delivery of molecules by acoustically stimulated microbubbles through transient membrane disruptions and enhanced endocytosis $[10,11]$. Ultrasound-microbubble therapy is also known to trigger apoptosis that may contribute to decreasing cell viability in combined treatment with cisplatin without increasing cytotoxic side effects [12-14]. 


\subsection{Cancer and Chemotherapy}

Cancer is a group of mutated cells that have abnormal characteristics and rapidly reproduce [15]. Mutations may be caused by various factors such as aging, DNA replication bypass, DNA repair mechanism errors, tobacco, obesity, genetic, and spontaneous $[15,16]$. Activating repair mechanisms that cause apoptosis, programmed cell death can control cellular mutations; however, in some cases the mutated cells group together to form a tumor, bypassing apoptosis and continuing to rapidly reproduce. A tumor is considered cancerous or malignant if it can metastasize, spread to other tissues throughout the body [16]. Metastasis commonly occurs when the tumor suppressor genes such as p53 or receptors on the mitochondria such as BAX or BAK are restricted by Bcl-2 up-regulation or when the two receptors form a heterodimer $[9,17]$. The bcl-2 receptors are proto-oncogene that assists anti-apoptotic activities, cell survival, growth and DNA replication [17]. Likewise, some mutated suppressor genes such as p53 can also inhibit apoptosis [18].

Treating cancer effectively with minimal side effects has been a challenge for several decades, as each treatment modality depends on the tumor characteristics such as size, type, depth, stage, and patient's age and health, often combining treatments improves efficacy [16, 19]. Some treatment modalities include radiation therapy, surgery, thermal therapy, chemotherapy, immunotherapy, ultrasound-microbubble therapy and hormone therapy $[5,10,19$, 20]. Chemotherapeutic agents are highly cytotoxic drugs, administered orally or injected through the blood that interferes with cellular properties leading to cell death $[16,19]$. Chemotherapeutics have three main classifications: alkylating agents (including platinum based drugs such as cisplatin), antimetabolites (such as 5-Flurouracil and Gemcitabine), and natural 
products (including antibiotics such as Doxorubicin and inhibitors such as Topotecan and Taxane) $[19,21,22]$.

\subsection{Platinum based Chemotherapeutic Agent Cisplatin}

Platinum based alkylating agent, cisplatin is clinically used as adjuvant therapy to treat bladder, head, neck and testicular cancers [2, 3, 23, 24]. Copper transporter (CTR1) or passive diffusion are primarily responsible for intracellular cisplatin accumulation; after which the platinum atoms preferentially bind to the $\mathrm{N}^{7}$ position of purine bases forming 1,2-intrastrand crosslink, and single or double strand breaks, interfering with DNA transcription and/or replication [2, 25-27]. cisplatin efficacy is often limited by cellular drug resistance that can be categorized by two responses: (1) dose-dependent resistance, inadequate binding of DNA, as a result of reduced drug uptake or cellular detoxification (glutathione and metallothioneins); and (2) increased drug tolerance, post-DNA binding, extensive activation of DNA repair mechanisms or heterodimer forming between Bcl-2 and Bax receptors preventing the release of cytochrome $\mathrm{c}$ from mitochondria leading to cell survival $[9,26,28]$. Administering high concentrations can often overcome cisplatin dose-dependent resistance; however, clinically cisplatin can have detrimental effects at high concentrations [23, 24].

\subsection{Ultrasound and Microbubbles}

Ultrasound is an acoustic wave propagating through soft-tissue medium by oscillatory motion of particles in the direction of propagation and interacting with tissue causes attenuation through scattering and absorption of the ultrasound energy. Absorption is the conversion of 
ultrasound energy to predominantly thermal energy that can be used for treatments such as tumor ablation from high intensity focused ultrasound [20]; while scattering redirects ultrasound energy, which can lead to biological effects on tissues such as cavitation from the interaction between the ultrasound wave and microbubbles [29].

Microbubbles are small bubbles of inert gas-encapsulated in a shell, generally less than 10 micrometers in diameter, and commonly composed of lipid, albumin or polymer protein shell [11]. The core consists of gases such as perflourocarbon or perflouropentane $[11,30]$. In the presence of ultrasound, microbubbles respond to pressure waves by gas expansion and compression depending on various factors: (1) microbubble characteristics such as diameter, gas core composition and outer shell properties, (2) ultrasound parameters such as frequency, peak negative pressure, duty cycle, pulse repetition frequency and exposure duration, and (3) environmental properties such as density of the surrounding medium.

Microbubbles, when exposed to an ultrasound pulse, can undergo stable or inertial cavitation [30]. Generally, microbubbles undergo linear oscillation around their equilibrium radius at low acoustic pressures; that is microbubbles compress and expand during positive and negative pressure peaks, respectively. With increasing pressure, the response of microbubbles becomes more non-linear emitting harmonics and sub-harmonic waves [30]. Whereas at higher pressures, microbubbles undergo inertial cavitation where the microbubble expands two times larger than its initial diameter, causing the microbubble to rapidly collapse $[11,30]$. This type of cavitation is governed by the inertia of the surrounding fluid during the expansion phase of the microbubble to collapse. During stable and inertial cavitation, microbubbles interact with biological tissues in various ways producing shear stress, fluid micro-jets, microstreaming, and shock waves [30]. 
Currently, microbubbles are used as ultrasound enhancing contrast agents for diagnostic imaging [11]. Microbubbles increase the scattering of ultrasound pulses and emit signals at the harmonics (such as $2 \mathrm{f}_{\mathrm{o}}$ and $3 \mathrm{f}_{\mathrm{o}}$ ), subharmonics (such as $\mathrm{f}_{\mathrm{o}} / 2$ ) and ultraharmonics (such as $3 \mathrm{f}_{\mathrm{o}} / 2$, $5 \mathrm{f}_{\mathrm{o}} / 2$ ) improving the blood-tissue image contrast compared to the ultrasound imaging without microbubbles [11]. Microbubbles have also demonstrated enhanced local drug and gene delivery to various cancerous tumors with minimal impact on surrounding cells $[10,11,31-34]$. It is postulated that the application of ultrasound-microbubbles (USMB) enhances delivery by transient cell membrane permeability and enhanced endocytosis as a result of stress on the cell membrane [13]. Additionally, USMB can induce cellular damage leading to cell lysis, apoptosis and cancer growth retardation [12, 35-37].

Integrated cavitation dose (ICD) has been used to measure microbubble (MB) cavitation activity using the passive cavitation detection method, which was shown to be correlated with hemolysis, sonoporation rate and cell viability for Levovist ${ }^{\circledR}$ and Optison ${ }^{\circledR}$ microbubbles $[38$, 39]. The passive cavitation detection method employs two transducers: One transducer emits an ultrasound pulse and the other passively receives the signal emitted by microbubbles undergoing stable and inertial cavitation.

\subsection{Chemotherapy and Ultrasound-Microbubbles}

Several studies have investigated the efficacy of chemotherapeutics with USMB; specifically doxorubicin (Dox), bleomycin (BLM), metronomic cyclophosphamide (MCTX), docetaxel, topotecan (Top), cisplatin (CDDP), and cetuximab [8, 10, 34, 40-45].

Lee et al. found combined treatment of USMB and Dox decreased cell viability, of retinoblastoma cells, by $\sim 16 \%$ compared to Dox treatment alone [44]. The treatment conditions 
included Artison microbubbles (Artison Corp.), $1 \mathrm{MHz}$ frequency, $0.94 \mathrm{MPa}$ peak negative pressure, and $10 \mathrm{~s}$ and $60 \mathrm{~s}$ exposure duration. The combined treatment enhanced Dox intracellular uptake after 10 seconds exposure duration, whereas the pore formation was visually observed after 60 seconds exposure duration. These findings suggest either pore formation was present and too small to observe, or cells took up Dox by enhancing other mechanisms such as endocytosis [44]. In another in vitro study using mouse mammary tumor (4T1) cells, where Dox was added several minutes post-USMB, cell viability significantly decreased at higher peak negative pressures compared to Dox only [45]. Results suggest USMB may have also activated other biological mechanisms responsible for enhanced cell death [45].

Combinational treatment of BLM and USMB on gingival squamous carcinoma (Ca9-22) cells treated with Optison microbubbles, $1 \mathrm{MHz}$ frequency, and 20s exposure duration showed nuclei condensation and degradation post treatment. These results suggest cells underwent apoptosis as a result of increased intracellular BLM uptake [34]. In vivo combinational treatment with BLM and USMB also demonstrated a reduction in tumor growth in mice (inoculated with Ca9-22) compared to each treatment alone [34].

An in vivo study on athymic mice (implanted with MDA-MB-231 breast cancer cells) showed significant tumor growth inhibition and prolonged survival with combined treatment of MCTX and USMB compared to the control groups [41]. Treatment conditions included Definity microbubbles, $1 \mathrm{MHz}$ frequency, $1.65 \mathrm{MPa}$ peak negative pressure, 50 bursts of $0.1 \mathrm{~ms}$ pulses 1 ms apart, repeated at 20s intervals for 3 minutes [41].

In vitro human breast cancer (MDA-MB-231) and human prostate cancer (PC3) cells were studied with Docetaxel in combination with USMB. Results indicated synergistic enhancement of combined treatment for MDA-MB-231 cells by 10 fold cell death compared to 
docetaxel alone [40]. PC3 results indicated a lower enhancement at $\sim 15 \%$ decrease in cell viability for combined treatment compared to docetaxel alone [40]. Results were dependent on treatment conditions that include Artenga microbubbles, $500 \mathrm{kHz}$ frequency, and $240 \mathrm{kPa}$ and $580 \mathrm{kPa}$ peak negative pressures [40]. An in vivo study conducted with athymic mice (implanted with PC3 prostate cancer cells) using combined treatment of USMB and docetaxel demonstrated enhanced necrosis and apoptosis, along with tumor shrinkage within 4-6 weeks, prolonged survival and enhanced growth inhibition relative to treatments with docetaxel alone and control groups [42]. Treatment conditions included Artenga microbubbles, $1 \mathrm{MHz}$ frequency, and 1.65MPa peak negative pressure [42].

In an in vitro study using retinoblastoma cells, viability decreased by $30 \%$ and $23.8 \%$ with combination treatment of ultrasound-microbubble and CDDP or Top, respectively, compared to the drug alone [46]. Treatment conditions were 100 $\mu \mathrm{M}$ (CDDP) and 30nM (Top), $1 \mathrm{MHz}$ frequency, Definity microbubbles, 10s exposure duration and 48-hours incubation with drug [46]. Likewise, combinational treatment of USMB and CDDP on canine thyroid adenocarcinoma cells also decreased cell viability by $\sim 30 \%$ compared to CDDP alone; and demonstrated transient membrane disruption [8]. Treatment conditions for this study were Sonazoid microbubbles, 1-90s exposure durations, $0.01 \mu \mathrm{M}$ CDDP concentration, $5 \mathrm{MHz}$ frequency, 7.7KHz peak negative pressure, and 5 minutes incubation with drug [8].

In vitro and in vivo studies for combined treatment of CDDP and USMB were conducted with different cell lines (Colon26 and EMT6 in vitro; HT29-luc in vivo). In vitro treatment conditions included $0-1 \mathrm{mM}$ CDDP concentration, $1 \mathrm{MHz}$ frequency, $250 \mathrm{~Hz}$ peak negative pressure, Avanti microbubbles, and 10s exposure duration [43]. Results for EMT6 and Colon26 demonstrated $\sim 20-30 \%$ decrease in survival fraction with increasing CDDP concentration 
compared to CDDP with ultrasound treatment alone (no microbubbles) [43]. Likewise in vivo results demonstrated a significant decrease in tumor volume with combined treatment of CDDP with USMB compared to control groups [43]. In vivo treatment conditions were $0.5-1.25 \mathrm{ug} / \mathrm{g}$ CDDP, $1 \mathrm{MHz}$ frequency, $1000 \mathrm{~Hz}$ peak negative pressure, Avanti microbubbles, and 60s exposure duration [43].

Furthermore, in vitro and in vivo studies on mice implanted with head and neck tumors were treated with USMB and CDDP or Cetuximab. Treatment conditions included $1 \mathrm{MHz}$ frequency, $10 \mu \mathrm{M}$ (in vivo) or $1 \mu \mathrm{M}$ (in vitro) CDDP and $100 \mu \mathrm{M}$ Cetuximab concentrations, and Definity microbubbles [10]. The combined treatment in vitro with CDDP reported significant $(\sim 65 \%)$ increase in cell death compared to CDDP alone [10]. Similarly in vivo results with combined treatments reported decrease in tumor size by $21 \%$ and $26 \%$ compared to CDDP and Cetuximab alone respectively [10]. The study suggested that transient membrane disruption was responsible for enhanced intracellular drug uptake, resulting in decreased cell death and tumor size for both drugs.

Although, the cell types and ultrasound-microbubble treatment conditions such as peak negative pressure, ultrasound frequency, exposure time and microbubble type vary among studies, a decrease in cell viability or tumor size has been reported for most chemotherapeutic agents, including CDDP. Thus, it can be postulated that USMB can enhance the efficacy of chemotherapeutic agents. However, it is not well known the effectiveness of USMB in improving therapeutic response in chemo-resistant cancer cells. 


\subsection{Hypothesis and Specific Objectives}

The purpose of this study is to use ultrasound-microbubble therapy to improve cisplatin efficacy in drug-resistant breast cancer cells by increasing intracellular drug accumulation. This study is guided by the hypothesis that ultrasound-microbubble therapy synergistically enhances cisplatin effectiveness in human breast cancer cells, MDA-MB-231, in part by increasing intracellular cisplatin concentration.

The specific objectives investigated in this study are:

(1) To measure cell viability following treatment with cisplatin, ultrasoundmicrobubbles and their combined treatment at varying ultrasound-microbubble and cisplatin conditions.

(2) To measure intracellular platinum concentration following treatment with three micromolar cisplatin and ultrasound-microbubbles, and to correlate intracellular platinum concentration with cell viability.

(3) To measure integrated cavitation dose and correlate it with cell viability and intracellular platinum concentration.

\section{References}

1. Siddik, Z.H., Cisplatin: mode of cytotoxic action and molecular basis of resistance. Oncogene, 2003. 22(47): p. 7265-7279.

2. Luo, T., et al., Electron transfer-based combination therapy of cisplatin with tetramethylp-phenylenediamine for ovarian, cervical, and lung cancers. Proceedings of the National Academy of Sciences of the United States of America, 2012. 109(26): p. 10175-10180.

3. Galluzzi, L., et al., Molecular mechanisms of cisplatin resistance. Oncogene, 2012. 31(15): p. 1869-1883.

4. Stewart, J.M., et al., Phenotypic heterogeneity and instability of human ovarian tumorinitiating cells. Proceedings of the National Academy of Sciences of the United States of America, 2011. 108(16): p. 6468-6473. 
5. Mack, K.M., R.G. Canada, and P.A. Andrews, The effects of terbium on the cellular accumulation of cisplatin in MDA-MB-231 human breast tumor cells. Cancer Chemotherapy and Pharmacology, 1997. 39(3): p. 217-222.

6. Ghezzi, A., et al., Uptake of antitumor platinum(II)-complexes by cancer cells, assayed by inductively coupled plasma mass spectrometry (ICP-MS). Journal of Inorganic Biochemistry, 2004. 98(1): p. 73-78.

7. Bernard, V., et al., Ultrasound and Cisplatin Combined Treatment of Human Melanoma Cells A375-the Study of Sonodynamic Therapy. Ultrasound in Medicine and Biology, 2012. 38(7): p. 1205-1211.

8. Sasaki, N., et al., Activation of Microbubbles by Short-Pulsed Ultrasound Enhances the Cytotoxic Effect of Cis-Diamminedichloroplatinum (Ii) in a Canine Thyroid Adenocarcinoma Cell Line in Vitro. Ultrasound in Medicine and Biology, 2012. 38(1): p. 109-118.

9. Yde, C.W. and O.G. Issinger, Enhancing cisplatin sensitivity in MCF-7 human breast cancer cells by down-regulation of Bcl-2 and cyclin D1. International Journal of Oncology, 2006. 29(6): p. 1397-1404.

10. Heath, C.H., et al., Microbubble Therapy Enhances Anti-tumor Properties of Cisplatin and Cetuximab In Vitro and In Vivo. Otolaryngology-Head and Neck Surgery, 2012. 146(6): p. 938-945.

11. Mo, S., et al., Ultrasound-enhanced drug delivery for cancer. Expert Opin Drug Deliv, 2012. 9(12): p. 1525-38.

12. Honda, H., Q.-L. Zhao, and T. Kondo, Effects of dissolved gases and an echo contrast agent on apoptosis induced by ultrasound and its mechanism via the mitochondriacaspase pathway. Ultrasound in medicine \& biology, 2002. 28(5): p. 673-82.

13. Wu, F., et al., Ultrasound Reverses Multidrug Resistance in Human Cancer Cells by Altering Gene Expression of Abc Transporter Proteins and Bax Protein. Ultrasound in Medicine and Biology, 2011. 37(1): p. 151-159.

14. Ashush, H., et al., Apoptosis induction of human myeloid leukemic cells by ultrasound exposure. Cancer Research, 2000. 60(4): p. 1014-1020.

15. Craig A. Almeida, S.A.B., Cancer: Basic Science and Clinical Aspects. 2010: Wiley, 2010.

16. Stein, A.B.P.G.S., The biology and treatment of cancer: understanding cancer. 2009.

17. Ruvolo, P.P., X. Deng, and W.S. May, Phosphorylation of Bcl2 and regulation of apoptosis. Leukemia, 2001. 15(4): p. 515-22.

18. Haldar, S., et al., Down-Regulation of Bcl-2 by P53 in Breast-Cancer Cells. Cancer Research, 1994. 54(8): p. 2095-2097.

19. Torpy, J.M.L., Cassio; Glass, Richard M, Cancer: The basics. JAMA, 2010.

20. Moros, E., Physics of thermal therapy : fundamentals and clinical applications. Imaging in medical diagnosis and therapy. 2013, Boca Raton, FL: CRC/Taylor \& Francis. xvi, 359 p.

21. Eckstein, N., Platinum resistance in breast and ovarian cancer cell lines. J Exp Clin Cancer Res, 2011. 30: p. 91.

22. Brown, V.S., T; Symonds, R Paul, Principles of chemotherapy and radiotherapy. Obstetrics, Gynaecology \& Reproductive Medicine, 2011. 21(12).

23. Florea, A.M. and D. Busselberg, Cisplatin as an anti-tumor drug: cellular mechanisms of activity, drug resistance and induced side effects. Cancers (Basel). 3(1): p. 1351-71. 
24. Florea, A.M. and D. Busselberg, Cisplatin as an anti-tumor drug: cellular mechanisms of activity, drug resistance and induced side effects. Cancers (Basel), 2011. 3(1): p. 135171.

25. Park, S. and S.J. Lippard, Redox State-Dependent Interaction of HMGB1 and CisplatinModified DNA. Biochemistry, 2011. 50(13): p. 2567-2574.

26. Basu, A. and S. Krishnamurthy, Cellular responses to Cisplatin-induced DNA damage. J Nucleic Acids. 2010.

27. Wang, D. and S.J. Lippard, Cellular processing of platinum anticancer drugs. Nature Reviews Drug Discovery, 2005. 4(4): p. 307-320.

28. Kelland, L.R., Preclinical perspectives on platinum resistance. Drugs, 2000. 59: p. 1-8.

29. Frenkel, V., Therapeutic ultrasound mechanisms to applications. Nova Science Publishers, 2011.

30. Pitt, W.G., G.A. Husseini, and B.J. Staples, Ultrasonic drug delivery--a general review. Expert opinion on drug delivery, 2004. 1(1): p. 37-56.

31. Karshafian, R., et al., Sonoporation by Ultrasound-Activated Microbubble Contrast Agents: Effect of Acoustic Exposure Parameters on Cell Membrane Permeability and Cell Viability. Ultrasound in Medicine and Biology, 2009. 35(5): p. 847-860.

32. Unger, E.C., et al., Local drug and gene delivery through microbubbles. Progress in cardiovascular diseases, 2001. 44(1): p. 45-54.

33. Bao, S., B.D. Thrall, and D.L. Miller, Transfection of a reporter plasmid into cultured cells by sonoporation in vitro. Ultrasound in medicine \& biology, 1997. 23(6): p. 953-9.

34. Iwanaga, K., et al., Local delivery system of cytotoxic agents to tumors by focused sonoporation. Cancer Gene Ther, 2007. 14(4): p. 354-63.

35. Kinoshita and K. Hynynen, Key factors that affect sonoporation efficiency in in vitro settings: The importance of standing wave in sonoporation. Biochem Biophys Res Commun, 2007. 359(4): p. 860-865.

36. Bai, W.K., et al., Treatment of PC-3 cells with ultrasound combined with microbubbles induces distinct alterations in the expression of Bcl-2 and Bax. Chinese Science Bulletin, 2013. 58(28-29): p. 3535-3540.

37. Al-Mahrouki, A.A., et al., Bioeffects of Ultrasound-Stimulated Microbubbles on Endothelial Cells: Gene Expression Changes Associated with Radiation Enhancement in Vitro. Ultrasound in Medicine and Biology, 2012. 38(11): p. 1958-1969.

38. Lai, C.-Y., et al., Quantitative relations of acoustic inertial cavitation with sonoporation and cell viability. Ultrasound in medicine \& biology, 2006. 32(12): p. 1931-41.

39. Chen, W.-S., et al., Inertial cavitation dose and hemolysis produced in vitro with or without Optison. Ultrasound in medicine \& biology, 2003. 29(5): p. 725-37.

40. Karshafian, R., et al. Enhancing chemotherapy by ultrasound and microbubbles: Effect of acousticpressure and treatment order in in vitro suspension of reast and prostate cancercells. in Proceedings - IEEE Ultrasonics Symposium.

41. Todorova, M., et al., Antitumor effects of combining metronomic chemotherapy with the antivascular action of ultrasound stimulated microbubbles. International Journal of Cancer, 2013. 132(12): p. 2956-2966.

42. Goertz, D.E., et al., Antitumor Effects of Combining Docetaxel (Taxotere) with the Antivascular Action of Ultrasound Stimulated Microbubbles. Plos One, 2012. 7(12).

43. Watanabe, Y., et al., Low-intensity ultrasound and microbubbles enhance the antitumor effect of cisplatin. Cancer Science, 2008. 99(12): p. 2525-2531. 
44. Lee, N.G., et al., Sonoporation enhances chemotherapeutic efficacy in retinoblastoma cells in vitro. Invest Ophthalmol Vis Sci, 2011. 52(6): p. 3868-73.

45. Ghoshal, G., S. Swat, and M.L. Oelze, Synergistic effects of ultrasound-activated microbubbles and doxorubicin on short-term survival of mouse mammary tumor cells. Ultrason Imaging, 2012. 34(1): p. 15-22.

46. Wang, A.H., S.; Berry, J.; Murphree, A.; Fawzi, A., Sonoporation Enhances Cisplatin and Topotecan activity against Y79 Retinoblastoma cells In Vitro. Invest Ophthalmol Vis Sci, 2011. 52.

47. Mymryk, J.S., E. Zaniewski, and T.K. Archer, Cisplatin Inhibits Chromatin Remodeling, Transcription Factor-Binding, and Transcription from the Mouse Mammary-Tumor Virus Promoter in-Vivo. Proceedings of the National Academy of Sciences of the United States of America, 1995. 92(6): p. 2076-2080.

48. Jelenc, J., et al., Low-frequency ultrasound in vitro: experimental system and ultrasoundinduced changes of cell morphology. 2013 36th International Convention on Information and Communication Technology, Electronics and Microelectronics (Mipro), 2013: p. 340-344.

49. Bliss, C.I., The toxicity of poisons applied jointly. Annals of Applied Biology, 1939. 26(3): p. 585-615.

50. Shimizu, M. and Rosenber.B, Similar Action to Uv-Irradiation and a Preferential Inhibition of DNA-Synthesis in Escherichia-Coli by Antitumor Platinum Compounds. Journal of Antibiotics, 1973. 26(4): p. 243-245.

51. Harder, H.C., R.G. Smith, and A.F. Leroy, Template Primer Inactivation by CisDichlorodiammine and Trans-Dichlorodiammine Platinum for Human DNA-Polymerase Alpha,Beta, and Rauscher Murine Leukemia-Virus Reverse-Transcriptase, as a Mechanism of Cytotoxicity. Cancer Research, 1976. 36(10): p. 3821-3829.

52. Szabo, T.L., DIAGNOSTIC ULTRASOUND IMAGING: INSIDE OUT. Textbook, 2005.

53. Bandura, D.R., et al., Mass Cytometry: Technique for Real Time Single Cell Multitarget Immunoassay Based on Inductively Coupled Plasma Time-of-Flight Mass Spectrometry. Analytical Chemistry, 2009. 81(16): p. 6813-6822.

54. Chang, Q., et al., Single-cell measurement of the uptake, intratumoral distribution and cell cycle effects of cisplatin using mass cytometry. International Journal of Cancer, 2015. 136(5): p. 1202-1209.

55. Tarapacki, C. and R. Karshafian, Enhancing laser therapy using PEGylated gold nanoparticles combined with ultrasound and microbubbles. Ultrasonics, 2015. 57: p. 3643.

56. Engineering fluorescent proteins.

57. Lawrie, A., et al., Microbubble-enhanced ultrasound for vascular gene delivery. Gene Ther, 2000. 7(23): p. 2023-7. 


\title{
2. Synergistic Cisplatin-induced cell death by ultrasound-
}

\section{microbubble mediated intracellular delivery in breast cancer cells}

\author{
Sheliza Jetha, Shadab Momin, Raffi Karshafian \\ Department of Physics, Ryerson University \\ Submitted to BMC Cancer
}

\begin{abstract}
Background: Ultrasound-microbubble therapy has been shown to improve therapeutic effect of chemotherapy. The underlying mechanism has been associated with enhanced drug delivery and and apoptosis. In this study, ultrasound-microbubble (USMB) potentiated therapy of cisplatinresistant breast cancer cells is investigated.

Methods: Human breast cancer (MDA-MB-231) cells in suspension $\left(2 \times 10^{6}\right.$ cells $/ \mathrm{mL}$ concentration and $0.6 \mathrm{~mL}$ volume) were treated with $\mathrm{CDDP}(3,30$ or $300 \mu \mathrm{M}), \mathrm{USMB}(0.5 \mathrm{MHz}$ pulse centered frequency, $16 \mu$ s pulse duration, $1 \mathrm{kHz}$ pulse repetition frequency, 60 s insonation time, peak negative pressures of 230,580 or $910 \mathrm{kPa}$, and Definity microbubbles at $0.8,1.7$ or $3.3 \% \mathrm{v} / \mathrm{v}$ volume concentration). During the ultrasound treatment, microbubble cavitation activity was measured using a $1 \mathrm{MHz}$ passive transducer. 48-hours post treatment, cell viability and intracellular platinum concentration were measured using the MTT assay and mass cytometry, respectively.
\end{abstract}

Results: Cell viability significantly decreased by $\sim 5$ fold with combined treatment of CDDP+USMB compared to CDDP alone $(\mathrm{p}<0.001)$ for all USMB treatment parameters, corresponding to 20 fold increase in cell death. The combined treatment of CDDP+USMB was 
synergistic, based on the bliss independence model $(\mathrm{p}<0.05)$, for three CDDP concentrations at peak negative pressures and microbubble concentrations: $230 \mathrm{kPa}+1.7 \% \mathrm{v} / \mathrm{v}, 580 \mathrm{kPa}+0.8 \% \mathrm{v} / \mathrm{v}$, and $580 \mathrm{kPa}+1.7 \% \mathrm{v} / \mathrm{v}$. Combined treatment also significantly increased intracellular CDDP concentration by $\sim 8$ fold compared to CDDP treatment alone. Cell death and intracellular CDDP concentration were correlated to microbubble cavitation activity presented by integrated cavitation dose, which increased with peak negative pressure and microbubble concentration.

Conclusion: Ultrasound-microbubbles mediated cisplatin intracellular accumulation synergistically enhances cisplatin induced cell death ( 20 fold) in human breast cancer cells, MDA-MB-231, partly through USMB-mediated intracellular drug enhancement ( $\sim 8$ fold). Integrated Cavitation Dose (ICD) is correlated with intracellular cisplatin accumulation and cell death, and appears to be a predictor of treatment efficacy.

Keywords: Cisplatin, ultrasound therapy, ultrasound and microbubble, microbubble cavitation, targeted drug delivery, chemosensitization, chemoenhancement 


\subsection{Introduction}

Efficacy of cisplatin, platinum based alkylating agent, depends on drug concentration and cancer type [1]. In cancers such as bladder, head, neck, ovarian, colorectal, lung and testicular, cisplatin triggers apoptosis by inducing DNA damage [2-4]; whereas in breast cancer, cisplatin effectiveness is limited due to cellular drug resistance [1,25, 47]. Insufficient DNA binding of cisplatin associated with reduced drug uptake or the activation of anti-apoptotic pathways associated with activation of cell survival mechanisms can induce cellular drug resistance $[2,5]$. Copper transporter (CTR1) and passive diffusion are primarily responsible for intracellular cisplatin accumulation. Thus, increasing intracellular cisplatin accumulation can increase DNA binding and consequently improving cisplatin efficacy. However, at high concentrations cisplatin can have detrimental effects $[3,6]$. Various methods such as ultrasound-microbubble enhanced drug delivery, down-regulation of Bcl-2 expression, sonodynamic therapy, and combinational drug therapy, are being investigated in enhancing cisplatin effectiveness [2, 7-10].

Ultrasound-microbubble therapy has previously been associated with anti-vascular biological effects, and enhanced drug delivery due to transient membrane disruptions and enhanced endocytosis $[8,10,31,40,47,48]$, as well as inducing cellular damage leading to cell lysis, apoptosis and cancer growth retardation [12, 35, 37]. Microbubbles, small bubbles of inert-gas encapsulated in a shell and generally less than $10 \mu \mathrm{m}$ in diameter, are used clinically in diagnostic ultrasound and experimentally as targeted drug delivery. The acoustic mechanism of ultrasound-microbubble enhanced drug delivery has been associated with stable and inertial microbubble cavitation inducing stress on the cell membrane through microstreaming, fluid micro-jets and shock waves [30]. The acoustic activity of microbubbles can be quantified using 
the Integrated Cavitation Dose (ICD) [39] and has been shown to be associated with hemolysis, sonoporation rate and cell viability for Levovist ${ }^{\circledR}$ and Optison ${ }^{\circledR}$ microbubbles [38].

The combined treatments, in vivo, of ultrasound-and-microbubbles with either docetaxel, metronomic cyclophosphamide (MCTX), or cisplatin (CDDP) have reported significant enhancements in necrosis and apoptosis, tumor shrinkage, prolonged survival and enhanced growth inhibition relative to treatments with drug alone and control groups [10, 41, 42]. Similarly in in vitro studies, the combined treatment of CDDP and USMB demonstrated $\sim 30 \%$ decrease in cell viability compared to CDDP alone, after 5 min incubation [8]. Based on these aforementioned studies ultrasound-microbubble therapy enhances chemotherapeutic efficacy, for particular ultrasound-microbubble parameters and cell types. However, limited insight is provided about a range of ultrasound-microbubble parameters and their relationship with enhanced intracellular drug accumulation and cell death with a drug-resistant cell lines. This study investigates ultrasound-microbubble therapy with cisplatin chemotherapy in enhancing cell death of cisplatin-resistant breast cancer cells. The hypothesis guiding this study is that ultrasound-microbubble therapy synergistically enhances cisplatin effectiveness in a cisplatinresistant human breast cancer cells in part by increasing intracellular drug concentration, and that the effectiveness of the combined treatment depends on microbubble acoustic activity. Cells are exposed to USMB, CDDP and their combined treatment and subsequently associated with intracellular drug accumulation and ICD.

\subsection{Materials and Methods}

Cells in suspension were exposed to cisplatin (479306, Sigma Aldrich Canada Co., Oakville, ON), pulsed ultrasound and Definity ${ }^{\circledR}$ microbubbles (Lantheus Medical Imaging Inc., Saint- 
Laurent, QC, CA) and their combination. Variations in cisplatin concentration $(0-300 \mu \mathrm{M})$, microbubble concentrations $(0.8 \%-3.3 \% \mathrm{v} / \mathrm{v})$ and peak negative pressures $(230-910 \mathrm{kPa})$ were investigated. Following treatment, cell viability was measured using MTT assay after 48 hours incubation time and synergism was assessed according to the bliss independence model [49]. In addition, the intracellular cisplatin concentration per cell was assessed by measuring platinum uptake for the $3 \mu \mathrm{M}$ CDDP condition with and without USMB using a mass cytometer (CyTOF2, Fludigm/Sickkids, Toronto, ON). Intracellular platinum data was analyzed using CytoBank and normalized 4-element calibration beads to determine cisplatin atoms per cell for each condition; the tuning solution was used to measure transmission efficiency. Furthermore, the cavitation dose of microbubbles was acquired using passive cavitation detection (PCD) and correlated to cell viability and intracellular cisplatin concentration.

\subsubsection{In vitro cell model}

A human epithelial breast cancer cell line, MDA-MB-231, was used as a cancer model for investigating the enhancement of cisplatin using USMB. Cells were cultured in RPMI-1640 media with $10 \%$ fetal bovine serum (FBS), grown in a $37^{\circ} \mathrm{C}$ incubator with $5 \% \mathrm{CO}_{2}$ and removed from flasks using trypsinization. Following the addition of cisplatin and microbubbles, samples with a total volume of $0.6 \mathrm{~mL}$ at a concentration of $2 \times 10^{6}$ cells $/ \mathrm{mL}$ were exposed to ultrasound treatment.

\subsubsection{Chemotherapy}

Cisplatin (479306, Sigma Aldrich Canada Co., Oakville, ON) concentrations studied were $0,3,30$, and $300 \mu \mathrm{M}$. Stock solution $[3 \mathrm{mM}$ ] from cisplatin powder form was diluted in MilliQ water [2]. Diluted stock solutions were stored at room temperature and used within 72 hours of dilution. Cisplatin (CDDP) binds preferentially to DNA at the $\mathrm{N}^{7}$ position of guanine 
bases creating 1,2-intrastrand cross-links, single strand and double strand breaks [2, 25]. These DNA intracellular events activate necrotic and apoptotic pathways, by inhibiting DNA transcription and replication $[50,51]$.

\subsubsection{Ultrasound microbubble agent}

Definity microbubbles were added to each treatment sample prior to ultrasound. These microbubbles comprise of a phospholipid shell filled with octoflouropropane gas and stored at $4^{\circ} \mathrm{C}$. One hour prior to activation, a microbubble vial was kept at room temperature to equilibrate, followed by activation using Vialmix for 45 seconds and left to rest for 5 minutes. Microbubbles were then resuspended by hand agitation for 10 seconds, and inverted for 30 seconds before venting with 18-gauge needle and extracted into a syringe. The extracted microbubbles were diluted in 1:4 ratios with RPMI-1640 media. Microbubble concentrations used in this study were $0.8 \%, 1.7 \%$ and $3.3 \% \mathrm{v} / \mathrm{v}$ (volume concentration).

\subsubsection{Ultrasound exposure system}

A schematic diagram of the ultrasound apparatus is illustrated in Figure 1A. A signal was generated by a waveform generator (AWG610, Tektronix, USA) and amplified by a power amplifier (AG series Amplifier, T\&C power conversion, Inc., USA) that was received by a 0.5 $\mathrm{MHz}$ single element transmit transducer of $38 \mathrm{~mm}$ diameter (IL0508HP, Valpey Fisher Inc., Hopkinton, MA, USA). The transducer was calibrated for acoustic pressures at focal point by using a needle hydrophone (HNA-0400; Onda corp., Sunnyvale, CA, USA). Treatment samples were loaded into the sample chamber and sealed with Parafilm. The sample chamber had 4 acoustic windows, each covered with Mylar membranes. A magnetic stir stick inside the sample chamber was used to mix the cells and microbubbles and ensure uniform distribution. Cells were exposed to ultrasound at $0.5 \mathrm{MHz}$ pulse centered-frequency for $60 \mathrm{~s}$ with $32 \mu \mathrm{s}$ pulse duration, 
$1 \mathrm{kHz}$ pulse repetition frequency, $3.2 \%$ duty cycle, and varying concentrations of Definity ${ }^{\circledR}$ microbubbles (Lantheus Medical Imaging Inc., Saint-Laurent, QC, CA). The peak negative pressures investigated in this study are 230,580 and $910 \mathrm{kPa}$.

\subsubsection{Cavitation dose: Passive Cavitation Detection}

Figure 1B shows the experimental set up for detecting cavitation activities of MBs. A 1.0MHz transducer $($ Diameter $=42 \mathrm{~mm}$, Focal length $=4.8 \mathrm{~cm}$; Valpey Fisher Inc., Hopkinton, MA) was mounted perpendicularly to the transmit transducer to passively detect the scattered signal from microbubbles during ultrasound exposure. Both transducers were focused at the

focal point where the sample chamber was positioned. The acoustic waves emitted by microbubbles were acquired in the form of time domain at every $5 \mathrm{~ms}$ for 60 s by the acquisition system (CompuScope MATLAB SDK, Lockport, IL, USA). The acquired signals were converted from time domain into frequency domain using FFT algorithm in MATLAB (Mathworks Inc., Natick, MA) and corrected for the bandwidth of the passive transducer [52]. A reference signal was acquired from cells suspended in media and subtracted from the cavitation measurements of MBs+cells suspended in media. The bandwidth-corrected and reference-signalsubtracted spectrums are denoted as $\mathrm{Y}_{\mathrm{Ri}}(\mathrm{f})$ where subscript i represent the segment number from 1 to 12000 . The microbubble cavitation activity was quantified using cavitation dose (CD), as defined by equation 2.1 , at the second harmonics $\left(2 \mathrm{f}_{0}\right)$ of the treatment frequency $\left(\mathrm{f}_{0}\right)$ and integrated over $0.75-1.25 \mathrm{MHz}$ ranges. The integrated cavitation dose (ICD), as defined by equation 2.2, was quantified over the 60 s insonation time [38].

$$
\begin{gathered}
C D_{i}=\int_{f-\frac{1}{2} \Delta f}^{f+\frac{1}{2} \Delta f} \boldsymbol{Y}_{\boldsymbol{R}_{\boldsymbol{i}}} d f \\
\mathrm{ICD}=\sum_{\mathrm{i}=1}^{\mathrm{i}=\frac{\text { TotalTime }(\mathrm{s})}{\operatorname{PRP}(\mathrm{s})}} \mathrm{CD}_{\mathrm{i}} \Delta \mathrm{t}
\end{gathered}
$$




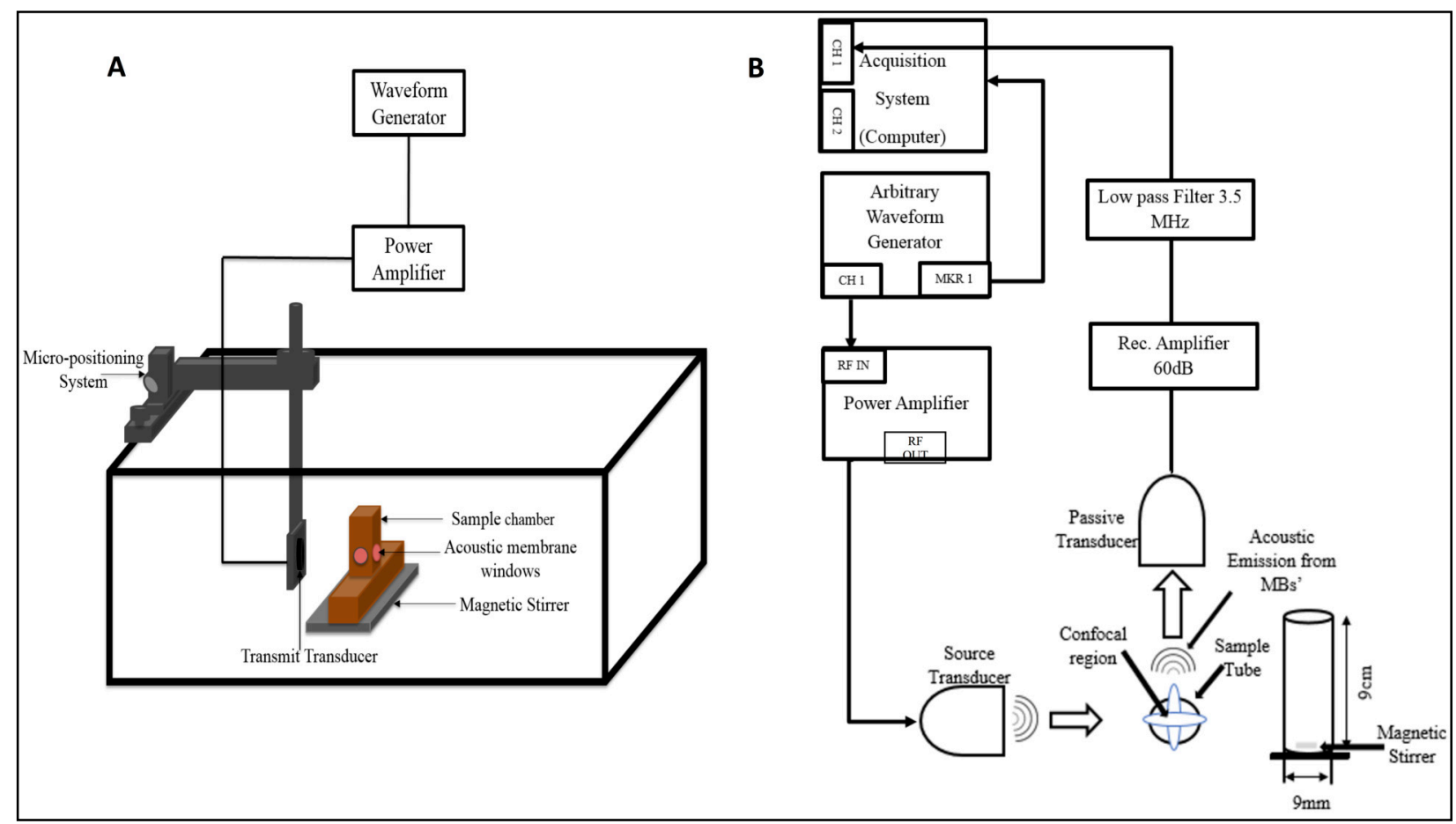

Figure 1: Schematics of (A) US exposure setup consisted of a waveform generator, power amplifier, transmit transducer and the sample chamber containing a magnetic stirrer; (B) Passive Cavitation Detection setup with an inclusion of passive transducer, $60 \mathrm{~dB}$ receiving amplifier, $3.5 \mathrm{MHz}$ low pass filter and the acquisition system.

\subsubsection{MTT-viability assay}

Cell viability was assessed using MTT assay, a colorimetric measurement of absorbance per well. MTT (M21128, Sigma Aldrich Canada Co., Oakville, ON) powder ( $8 \mu \mathrm{g})$ was diluted in $10 \mathrm{~mL}$ of media (RPMI 1640) with $1.12 \mathrm{~mL}$ of phosphate buffer solution (PBS). After each treatment, cells were plated $(100 \mu \mathrm{L} /$ well, 8000 cells/well) in 96-well plates and incubated for 48 hours. After incubation, cells were aspirated and suspended in MTT solution $(100 \mu \mathrm{L} /$ well) for 45 minutes. After 45 minutes, the MTT solution was aspirated and DMSO $(100 \mu \mathrm{L} /$ well $)$ was added to each plate. Absorbance measurements were taken using a plate reader at 570 and $650 \mathrm{~nm}$. Absorbance readings at $650 \mathrm{~nm}$ was treated as background and subtracted from $570 \mathrm{~nm}$ 
measurements. Treatment samples were distributed in columns (8 wells/column/independent treatment) and averaged per independent treatment. Independent treatment samples were repeated 2-3 times per experiment and each experiment was repeated thrice.

\subsubsection{Platinum quantification using mass cytometer}

The intracellular CDDP concentration was assessed using a mass cytometer technique. The system injects individual cells stained with stable isotope tags and measures the atomic composition of the cell [53]. This measurement is performed through vaporization, atomization, and ionization of individual cells by high temperature Inductive Coupling Plasma (ICP), which generates mass spectra of each cell by time of flight mass spectrometry [54]. The mass cytometer is also capable of measuring intracellular heavy metals such as platinum and iodine [54]. However, the concentrations of these heavy metals must be below a particular threshold to ensure no damage is done to the detector. As such, the intracellular CDDP concentration was assessed for treatment conditions at only $3 \mu \mathrm{M}$ CDDP. Higher CDDP concentration $(30 \mu \mathrm{M})$ was also tested, but due to cytometer limitations the acquisition was terminated to avoid damage to the system; thus, no reliable data was obtained for analysis at higher CDDP concentrations.

Platinum quantification measurements were taken for MDA-MB-231 cells in suspension (RPMI-1640) exposed to (Pneg 230-910 kPa) pulse waved ultrasound, in the presence of ( 0 and $3 \mu \mathrm{M})$ cisplatin and $(0.8-3.3 \% \mathrm{v} / \mathrm{v})$ Definity ${ }^{\circledR}$ microbubbles after 48-hour incubation. Enhanced uptake by ultrasound-microbubbles and treatment order were studied. Following ultrasound treatment, samples were diluted to a total volume of $5 \mathrm{~mL}$ keeping cisplatin concentrations constant and entirely plated in petri dishes. After 48-hours incubation, cells were scraped from the petri plates, centrifuged, washed, fixed (16\% PFA, 1:10 dilution) and stained with iridium intercalate (Ir-193) for cell identification; followed by two final washes using pure water and 
counted in a final volume of $100 \mu \mathrm{L}$. Before cells were spiked into mass cytometer, 4-element calibrations beads (1:10 dilution in pure water) were added to each sample for a final volume of $530 \mu \mathrm{L}$. Tuning solution was run before and after the experiment to determine transmission efficiency and all samples were normalized to the 4-element calibration beads. Analysis was completed using CytoBank software. The platinum/cell measurements were all adjusted for background found in the control sample. The intracellular platinum concentration was derived using a previously estimated volume of a single cell to be $2 \mathrm{pl} \mathrm{[6].}$

\subsubsection{Statistical analysis}

Data was presented as the mean \pm standard error of the mean (SEM). Cell viability and uptake measurements were normalized to controls (no ultrasound, microbubble or cisplatin treatment) for each experiment. Statistical analysis was performed using non-parametric t-test and statistical significance of $\mathrm{p}<0.05$. Synergism of cell viability between treatment conditions was evaluated using the Bliss Independence criteria $[49,55]$. Cell viability, intracellular CDDP concentration and ICD relationship was statistically analyzed by correlation test.

\subsubsection{Treatment conditions}

A total of 48 treatment conditions including treatment order were accessed for cell viability and accumulation where each condition was repeated 6-9 times (refer to Table 1 for specific treatment conditions). In order to measure treatment order, only microbubbles were added prior to ultrasound for USMB +15 mins + CDDP samples, cisplatin was added 15 minutes post-ultrasound treatment at the appropriate concentrations. The following Figure 2 illustrates treatment order and process. Table 1 represents the microbubble concentration and ultrasound pressure combinations studied for each cisplatin concentration and treatment order. 


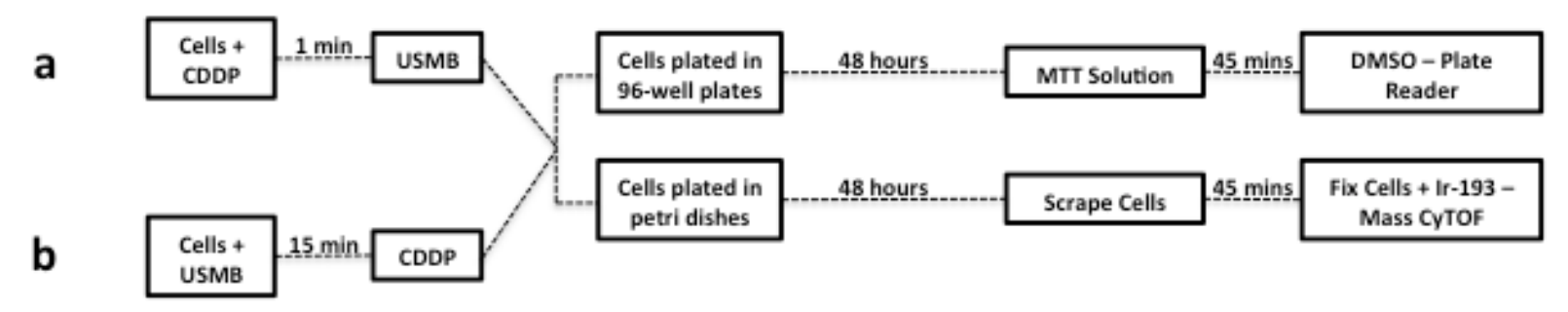

Figure 2: Schematic diagram of treatment conditions for MTT assay viability experiments and mass cytomtery uptake measurements with USMB.

Table 1: Ultrasound peak negative pressures studied at each microbubble concentration

\begin{tabular}{|l|l|l|l|l|}
\hline Microbubble Concentration (\% v/v) & $\mathbf{0 \%}$ & $\mathbf{0 . 8 \%}$ & $\mathbf{1 . 7 \%}$ & $\mathbf{3 . 3 \%}$ \\
\hline Pressures (kPa) & 0 & 580 & $230,580,910$ & 580 \\
\hline CDDP Concentration $(\mu \mathbf{M})$ & $0,3,30,300$ & $0,3,30,300$ & $0,3,30,300$ & $0,3,30,300$ \\
\hline
\end{tabular}

\subsection{Results}

To study the therapeutic effect of ultrasound-microbubble (USMB) with cisplatin (CDDP) on MDA-MB-231 cells measurements of cell viability, intracellular CDDP concentration and integrated cavitation dose (ICD) measurements were performed. Overall USMB enhanced the therapeutic effect of CDDP by decreasing cell viability and increasing intracellular CDDP concentration in MDA-MB-231 cells. Combined treatment results demonstrated at low peak negative pressures $(230-580 \mathrm{kPa})$ and microbubble concentrations $(0.8-$ $1.7 \% \mathrm{v} / \mathrm{v}$.) synergistic enhancement of cell death. Additionally, ICD at the second harmonic increased with peak negative pressure and microbubble concentration, and correlated with cell death and intracellular CDDP concentration. 


\subsubsection{Cell viability with USMB and cisplatin}

Figure 3 illustrates the effects of acoustic pressure, microbubble concentration, and cisplatin concentration on cell viability. In general, USMB decreased cell viability when combined with CDDP. USMB enhanced effectiveness of CDDP in killing cancer cells by $\sim 20$ fold compared to chemotherapy alone. For example, CDDP alone at $3 \mu \mathrm{M}$ has a cell viability of $96 \pm 4 \%$ compared to $19 \pm 4 \%$ for combined treatment with $910 \mathrm{kPa}$ peak negative pressure, $1.7 \% \mathrm{v} / \mathrm{v}$ microbubble concentration and $3 \mu \mathrm{M}$ CDDP concentration. In addition, USMB enhanced efficacy of CDDP in terms of chemotherapy dosage by $\sim 100$ fold while maintaining a similar cell death; cell viability of $42 \pm 3 \%$ was achieved with USMB $(580 \mathrm{kPa}+1.7 \% \mathrm{v} / \mathrm{v})$ and $3 \mu \mathrm{M}$ CDDP compared to $37 \pm 5 \%$ with $300 \mu \mathrm{M}$ CDDP dose alone. A statistically significant decrease in cell viability was observed for the combined treatment of USMB and CDDP (both $\mathrm{CDDP}+\mathrm{USMB}$ and $\mathrm{USMB}+15$ mins $+\mathrm{CDDP})$ compared to the CDDP alone for all treatment conditions. Cell viability decreased with CDDP concentration and in the presence of USMB cell viability plateaued with increasing acoustic pressure and microbubble concentration. For example, cell viability at $580 \mathrm{kPa}+1.7 \% \mathrm{v} / \mathrm{v}$ for $30 \mu \mathrm{M}$ was $18 \pm 1 \%$ and $11 \pm 1 \%$ for $300 \mu \mathrm{M}$, while cell viability at $910 \mathrm{kPa}+1.7 \% \mathrm{v} / \mathrm{v}$ was $17 \pm 3 \%$ and $15 \pm 2 \%$ respectively. However, cell viability, treated with USMB alone, decreased with acoustic pressure and MB concentration. For example, cell viabilities for $230 \mathrm{kPa}+1.7 \% \mathrm{v} / \mathrm{v}$ and $910 \mathrm{kPa}+1.7 \% \mathrm{v} / \mathrm{v}$ were $81 \pm 5 \%$ and $32 \pm 4 \%$ respectively; and $76 \pm 4 \%$ and $45 \pm 3 \%$ for $580 \mathrm{kPa}+0.8 \% \mathrm{v} / \mathrm{v}$ and $580 \mathrm{kPa}+3.3 \% \mathrm{v} / \mathrm{v}$ respectively. Furthermore, the treatment order of combined treatment did not significantly alter cell viability under conditions of 48-hour drug-incubation; cell viability at each of the treatment conditions was not statistically different between the different treatment orders. One example of cell 
viability with altered treatment order was $19 \pm 4 \%$ and $26 \pm 5 \%$ for $3 \mu \mathrm{M}+580 \mathrm{kPa}+1.7 \% \mathrm{v} / \mathrm{v}$ and $580 \mathrm{kPa}+1.7 \% \mathrm{v} / \mathrm{v}+15 \mathrm{mins}+3 \mu \mathrm{M}$ respectively.
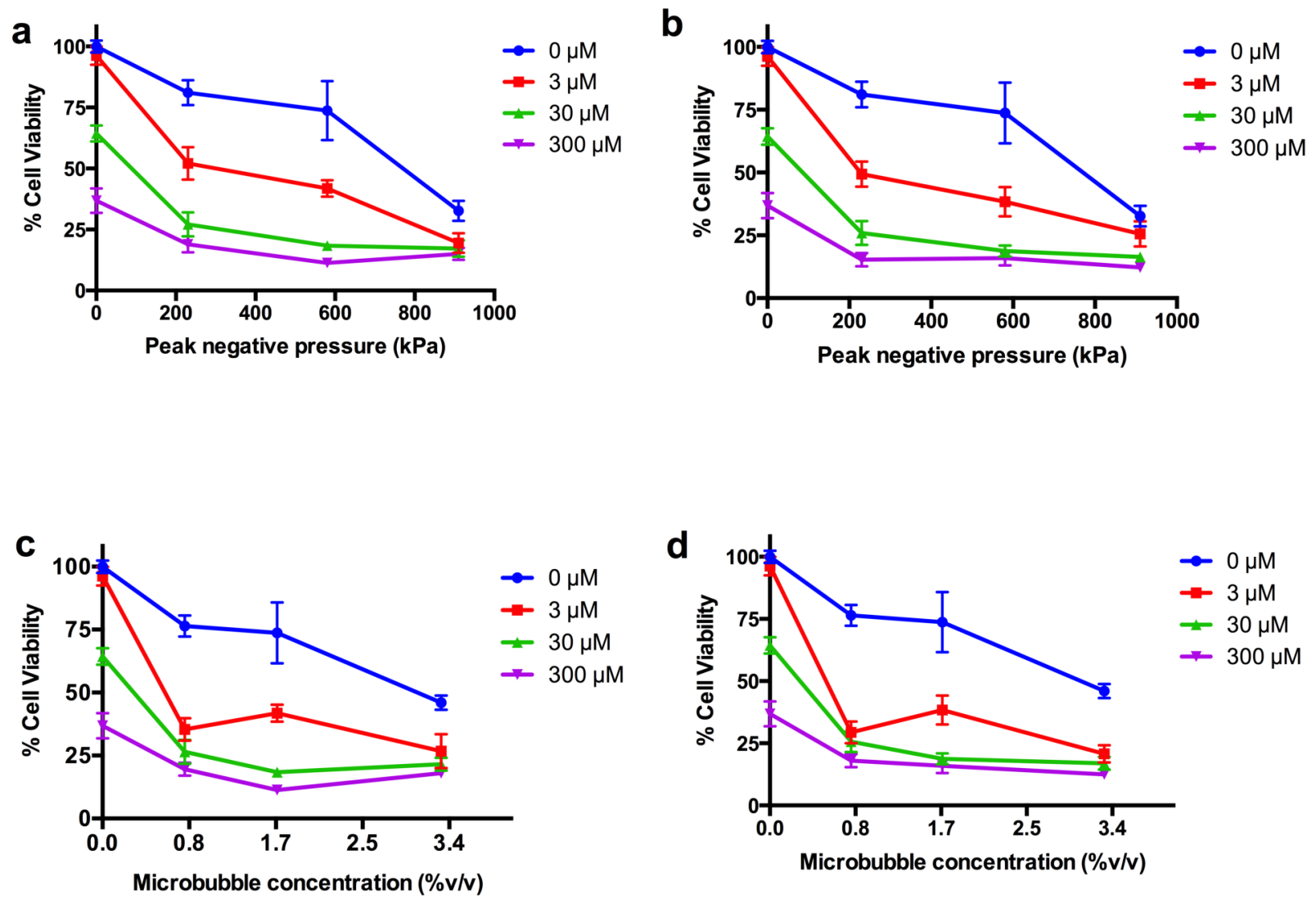

Figure 3: Percent cell viability of breast cancer cells for both CDDP alone and combinational treatments CDDP+USMB and USMB+15mins+CDDP. All percent viability values are normalized to no treatment controls, measured using MTT assay. ( $a$ and $b$ ) represent the different treatment orders (CDDP+USMB and USMB +15 mins + CDDP respectively) at $1.7 \% \mathrm{v} / \mathrm{v}$ microbubble concentration. (c and d) represent different treatment orders (CDDP $+\mathrm{USMB}$ and $\mathrm{USMB}+15 \mathrm{mins}+\mathrm{CDDP}$ respectively) at $580 \mathrm{kPa}$ peak negative pressure. Each line on the graphs represents a different CDDP concentration $(0-300 \mu \mathrm{M})$. Error bars represent standard error of the mean, where $\mathrm{n}=6-9$ samples [56].

Figure 4 illustrates the synergistic effect of the combined treatment by statistically (nonparametric t-test) comparing the expected (additive effect of USMB and cisplatin treatments) cell viability values with that of experimental cell viability values. Statistically significant 
experimental cell viabilities compared to expected viabilities based on the independence criterion are considered synergistically enhanced treatment conditions; while experimental cell viabilities that are at par with expected values and not statistically different are considered additive treatment conditions. Synergism with the combined treatment of USMB and CDDP was observed at lower pressures and microbubble concentrations, including $230 \mathrm{kPa}+1.7 \% \mathrm{v} / \mathrm{v}$, $580 \mathrm{kPa}+0.8 \% \mathrm{v} / \mathrm{v}$ and $580 \mathrm{kPa}+1.7 \% \mathrm{v} / \mathrm{v}$, for all CDDP concentrations. At higher pressures and microbubble concentrations, including $910 \mathrm{kPa}+1.7 \% \mathrm{v} / \mathrm{v}$ and $580 \mathrm{kPa}+3.3 \% \mathrm{v} / \mathrm{v}$, the effect of the combined treatment was additive. The results indicate that at relatively lower USMB conditions (acoustic pressure and microbubble concentration), the USMB therapy is capable of synergistically enhancing chemotherapy efficacy. Whereas at higher USMB conditions, cell death is induced by USMB therapy. 

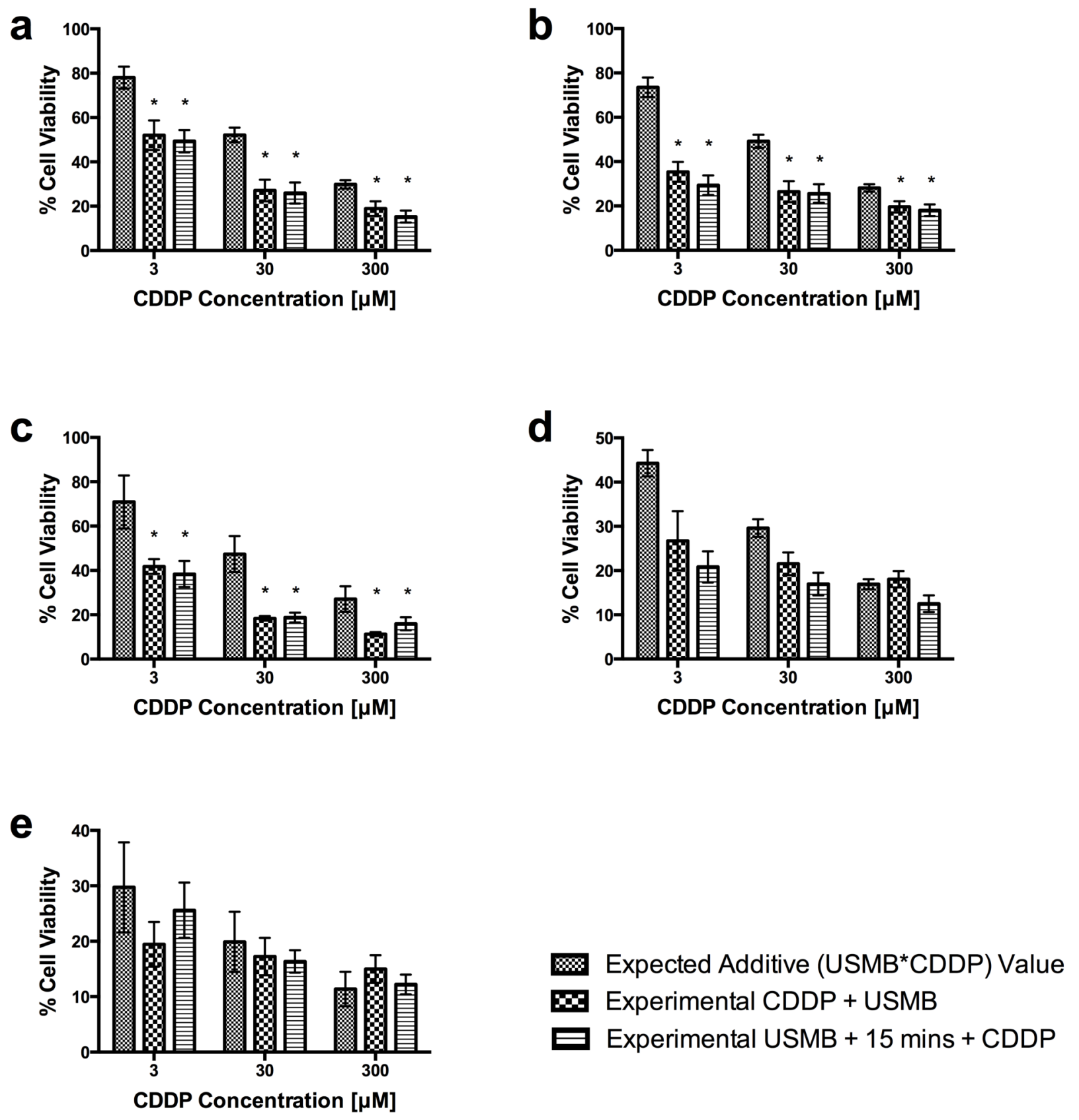

Figure 4: Comparison between expected additive cell viability and experimental cell viability for each treatment condition in the presence of CDDP and USMB for both treatment orders. Figures represented are (a) peak negative pressure $230 \mathrm{kPa}$ with $1.7 \% \mathrm{v} / \mathrm{v}$ microbubble concentration; (b) peak negative pressure $580 \mathrm{kPa}$ with $0.8 \% \mathrm{v} / \mathrm{v}$ microbubble concentration; (c) peak negative pressure $580 \mathrm{kPa}$ with $1.7 \% \mathrm{v} / \mathrm{v}$ microbubble concentration; (d) peak negative pressure $580 \mathrm{kPa}$ with $3.3 \% \mathrm{v} / \mathrm{v}$ microbubble concentration; and (e) peak negative pressure $910 \mathrm{kPa}$ with $1.7 \% \mathrm{v} / \mathrm{v}$ microbubble concentration. Statistical analysis was performed for each comparison to determine synergistic 
and additive effects with a non-parametric $\mathrm{t}$-test $(\mathrm{p}<0.05)$ and the bliss independence model, where $*$ represents treatment conditions that have been deemed to be synergistic based on he bliss independence model; and error bars represent standard error of the mean.

\subsubsection{Intracellular cisplatin}

Figure 5 illustrates intracellular CDDP concentration after CDDP treatment in the presence and absence of USMB treatment at varying microbubble concentrations and peak negative pressures. Platinum atoms per cell ( $\mathrm{Pt}$ atoms/cell) were obtained after 48-hour incubation by mass cytometry following treatment with CDDP $(3 \mu \mathrm{M})$ concentration and USMB $($ peak negative pressures $=0,230,580$ and $910 \mathrm{kPa} ; \mathrm{MB}$ concentration $=0,0.8,1.7$ and $3.3 \%$ $\mathrm{v} / \mathrm{v})$. USMB treatment significantly increased the intracellular platinum concentration. A statistically higher intracellular CDDP concentration was observed in CDDP+USMB $(12 \pm 2 \mu \mathrm{M}$ to $24 \pm 7 \mu \mathrm{M})$ compared to CDDP alone $(3 \pm 1 \mu \mathrm{M})$. On average, the intracellular CDDP concentration increased with peak negative pressure and microbubble concentration. Intracellular CDDP concentration increased by $\sim 8$ fold at peak negative pressure $910 \mathrm{kPa}$ compared to $\sim 4$ fold at 230kPa. However, no statistical difference for intracellular CDDP concentration was observed between the combined treatments of $230 \mathrm{kPa}+1.7 \% \mathrm{v} / \mathrm{v}, 580 \mathrm{kPa}+0.8 \% \mathrm{v} / \mathrm{v}$ and $580 \mathrm{kPa}+1.7 \% \mathrm{v} / \mathrm{v}$; or $580 \mathrm{kPa}+1.7 \% \mathrm{v} / \mathrm{v}, 580 \mathrm{kPa}+3.3 \%$ and $910 \mathrm{kPa}+1.7 \% \mathrm{v} / \mathrm{v}$. In addition, the intracellular CDDP concentration was comparable for both treatment orders at USMB conditions $580 \mathrm{kPa}+1.7 \%$ and $3 \mu \mathrm{M}$ CDDP concentration. 

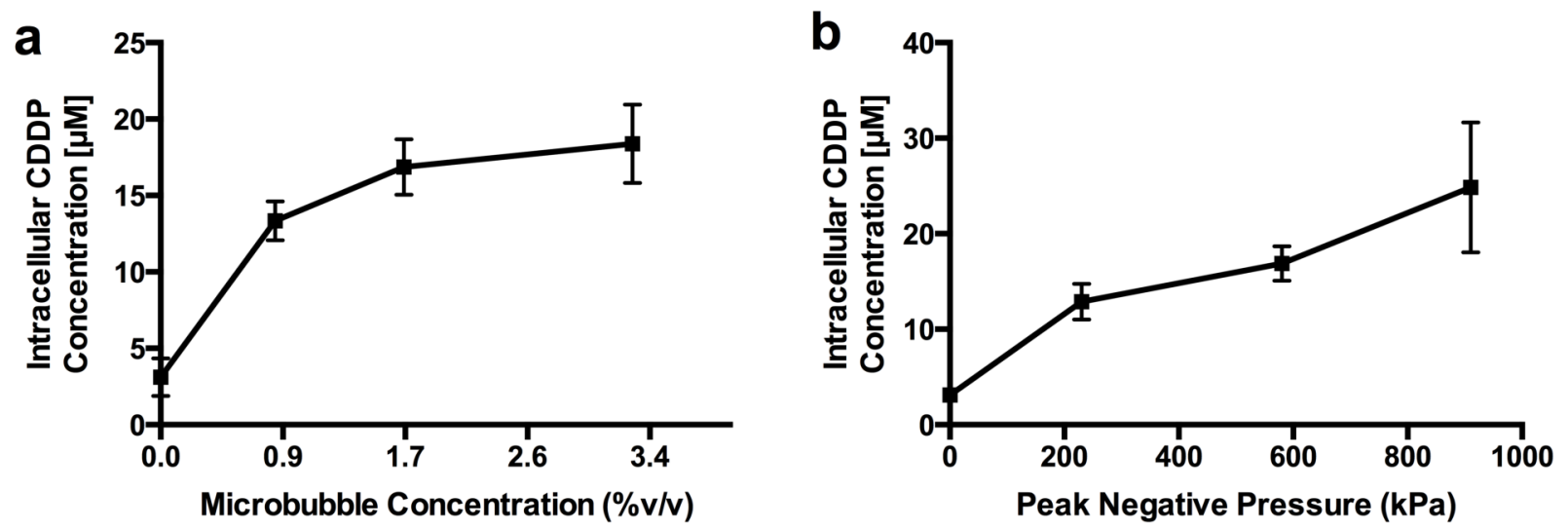

Figure 5: Quantified intracellular CDDP concentration for $3 \mu \mathrm{M}$ CDDP concentration with or without USMB (a) at varying peak negative pressures with fixed $1.7 \% \mathrm{v} / \mathrm{v}$ microbubble concentration, and (b) at varying microbubble concentrations with fixed $580 \mathrm{kPa}$ peak negative pressure. Error bars represent standard error of the mean, where $\mathrm{n}=6$ samples.

\subsubsection{Integrated cavitation dose (ICD)}

Figure 6 represents the integrated cavitation dose (ICD) at the second harmonics for varying microbubble concentrations $(0.8,1.7,3.3 \% \mathrm{v} / \mathrm{v})$ and peak negative pressures $(230,580$, $910 \mathrm{kPa}$ ) at 16 cycles for $60 \mathrm{~s}$ of a $0.5 \mathrm{MHz}$ pulse centered frequency wave. ICD increases with acoustic pressure and microbubble concentration. ICD increased by $\sim 2$ fold when pressure increased from $580 \mathrm{kPa}$ to $910 \mathrm{kPa}$ at $1.7 \% \mathrm{v} / \mathrm{v}$ (Figure 7a). Similarly, the ICD increased by $\sim 2$ fold (from $\sim 5$ to $\sim 10$ ) with doubling microbubble concentration $(1.7 \%$ versus $3.3 \% \mathrm{v} / \mathrm{v})$. In addition, a similar ICD was achieved at $580 \mathrm{kPa}+3.3 \% \mathrm{v} / \mathrm{v}$ and $910 \mathrm{kPa}+1.7 \% \mathrm{v} / \mathrm{v}$ with $10 \pm 1$ and $12 \pm 1$ values, respectively. Overall, increasing peak negative pressure or microbubble concentration resulted in an increase in integrated cavitation dose. 

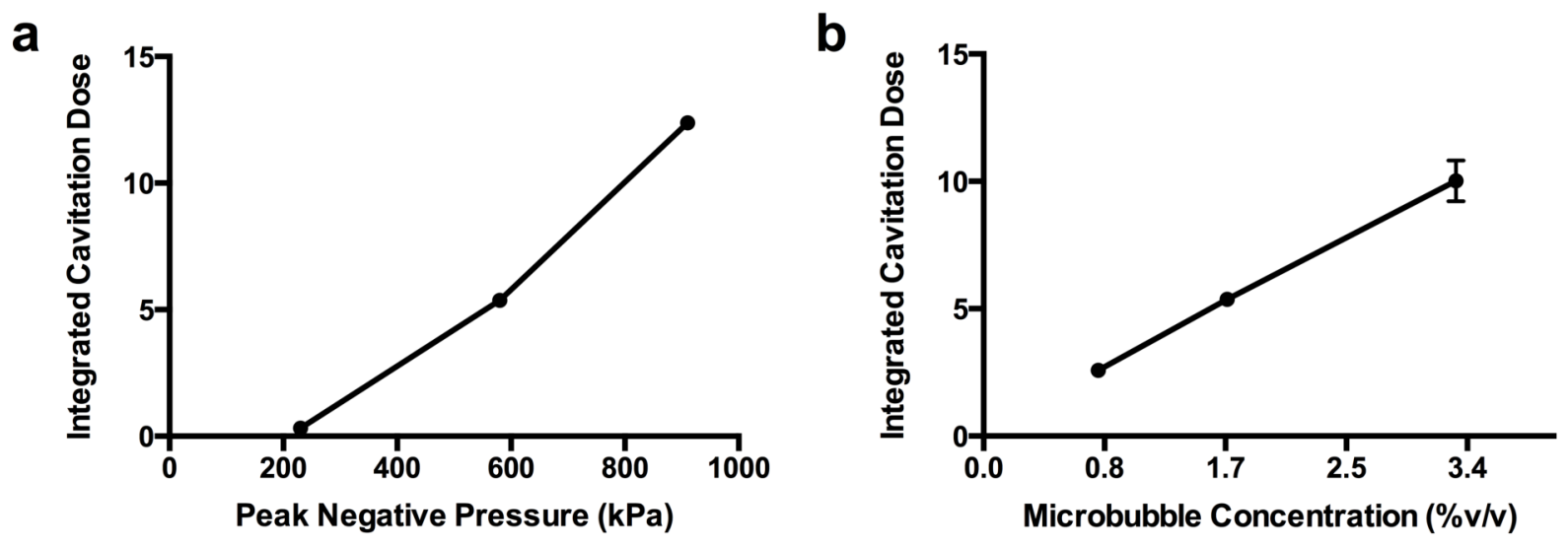

Figure 6: Integrated cavitation dose of the second harmonic frequency at (a) different acoustic pressures (230, 580, $910 \mathrm{kPa})$ and (b) microbubble concentrations $(0.8,1.7,3.3 \% \mathrm{v} / \mathrm{v})$ received with $1 \mathrm{MHz}$ transducer for 60 s of exposure time. Error bars represent standard error of the mean, where $n=3$ samples.

\subsubsection{Cell viability, intracellular cisplatin and ICD}

Figure 7a shows the relationship between increased intracellular CDDP concentrations with cell viability for each treatment condition. Data illustrates an inverse relationship $\left(\mathrm{R}^{2}=\right.$ 0.8770) between CDDP intracellular accumulation and cell viability; as intracellular CDDP concentration increases cell viability decreases. Figure $7 \mathrm{~b}$ shows the relationship between cell viability and ICD for conditions with varying acoustic pressures $(230,580,910 \mathrm{kPa})$ and microbubble concentrations $(0.8,1.7,3.3 \% \mathrm{v} / \mathrm{v})$. Cell viability decreases as ICD increases with and without CDDP treatment. An inverse correlation exists between cell viability and integrated cavitation dose with $\mathrm{R}^{2}$ values of 0.9398 for USMB only and 0.8435 for combined treatment (CDDP+USMB). In addition, the combined treatment was synergistic for ICDs less than $\sim 6$ and additive for ICDs more than $\sim 10$. Figure $7 \mathrm{c}$ represents the relationship between intracellular CDDP concentration and integrated cavitation dose for combined treatments with increasing peak negative pressure $(230 \mathrm{kPa}-910 \mathrm{kPa})$ and increasing microbubble concentration $(0.8 \% \mathrm{v} / \mathrm{v}-$ $3.3 \% \mathrm{v} / \mathrm{v})$. As both intracellular CDDP concentration and ICD increase with increasing peak 
negative pressure and microbubble concentration, the two are linearly correlated based on the statistical correlation test with $\mathrm{R}^{2}=0.8840$.

a

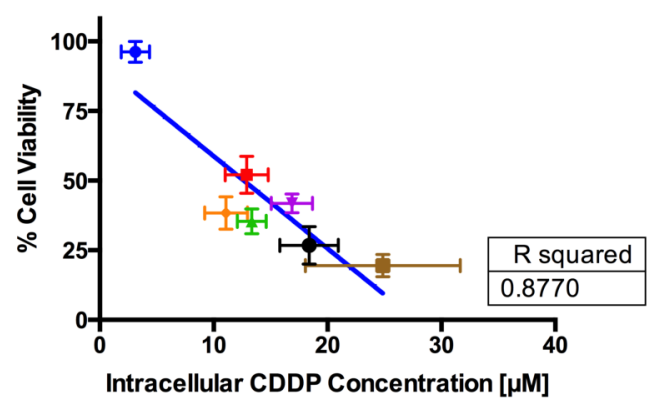

- $3 \mu \mathrm{M}$

- $3 \mu \mathrm{M}+230 \mathrm{kPa}+1.7 \%$

- $3 \mu \mathrm{M}+580 \mathrm{kPa}+0.8 \%$

v $3 \mu \mathrm{M}+580 \mathrm{kPa}+1.7 \%$

- $580 \mathrm{kPa}+1.7 \%+15 \mathrm{mins}+3 \mu \mathrm{M}$

- $3 \mu \mathrm{M}+580 \mathrm{kPa}+3.3 \%$

- $3 \mu \mathrm{M}+910 \mathrm{kPa}+1.7 \%$
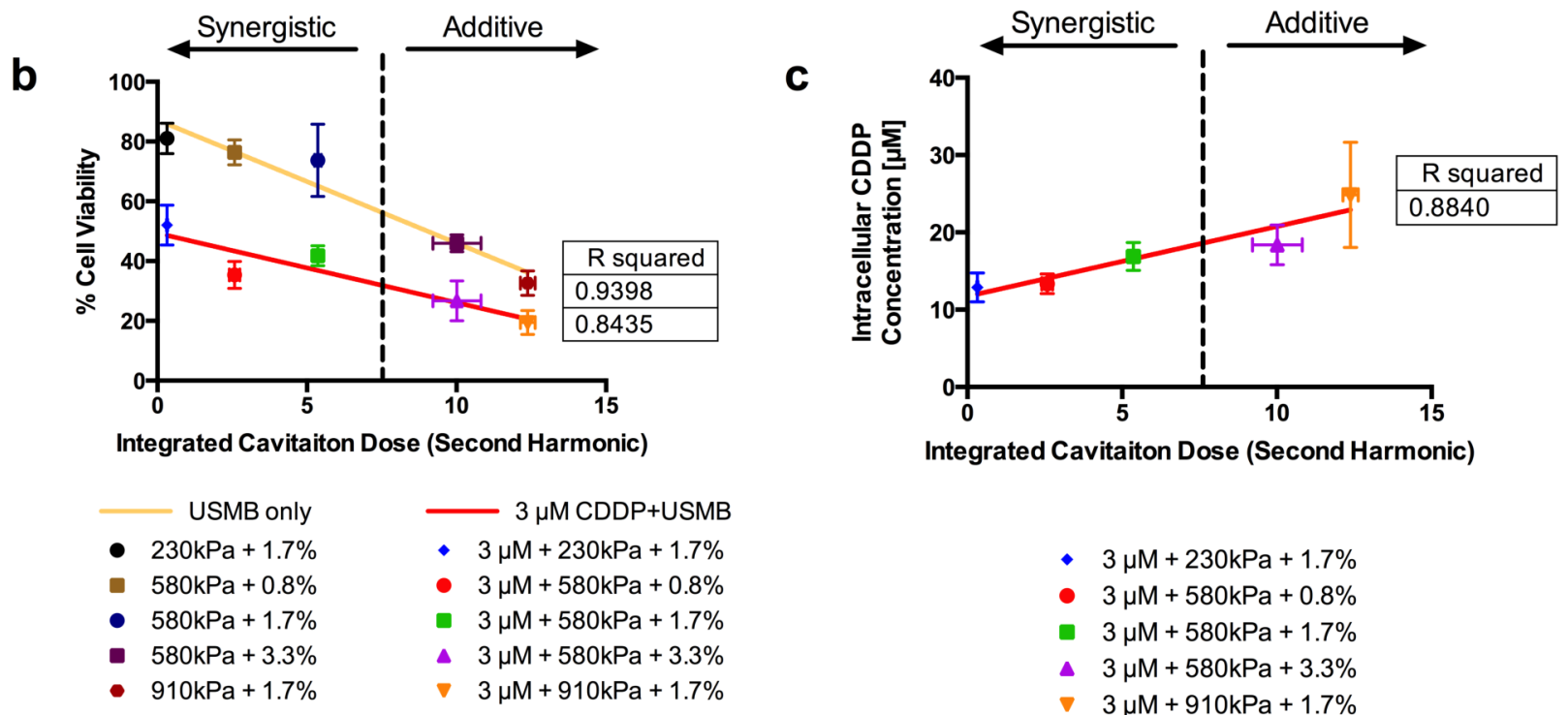

- $3 \mu \mathrm{M}+230 \mathrm{kPa}+1.7 \%$

- $3 \mu \mathrm{M}+580 \mathrm{kPa}+0.8 \%$

- $3 \mu \mathrm{M}+580 \mathrm{kPa}+1.7 \%$

$\Delta \quad 3 \mu \mathrm{M}+580 \mathrm{kPa}+3.3 \%$

- $3 \mu \mathrm{M}+910 \mathrm{kPa}+1.7 \%$

Figure 7: (a) Cell viability correlated with intracellular platinum concentration for $3 \mu \mathrm{M}$ CDDP concentration with or without USMB at varying peak negative pressures with fixed $1.7 \% \mathrm{v} / \mathrm{v}$ microbubble concentration and varying microbubble concentrations with fixed 580kPa peak negative pressure. (b) The correlation between cell viability of MDA-MB-231 breast cancer cells and second harmonic ICD at varying peak negative pressure $(230,580,910 \mathrm{kPa})$ and microbubble concentration $(0.8,1.7,3.3 \% \mathrm{v} / \mathrm{v})$. (c) Correlation between intracellular CDDP concentration of MDA-MB-231 breast cancer cells and second harmonics ICD at varying peak negative pressure $(230,580,910 \mathrm{kPa})$ and microbubble concentration $(0.8,1.7,3.3 \% \mathrm{v} / \mathrm{v})$. Frequencies were received with $1 \mathrm{MHz}$ transducer (16 cycle pulse using a $0.5 \mathrm{MHz}$ treatment transducer and $60 \mathrm{~s}$ exposure time). Dashed line used to split the ICD axis 
represents regions of CDDP+USMB conditions as synergistic verses additive. Error bars represent standard mean error.

\subsection{Discussion}

The application of USMB therapy synergistically enhanced the therapeutic effectiveness of CDDP of in vitro human breast cancer cells that demonstrated drug resistance to CDDP; a viability of $\sim 65 \%$-to- $96 \%$ was achieved when treated with $3-30 \mu \mathrm{M}$ of CDDP. Cell viability decreased by $\sim 5$ fold with the combined treatment of USMB+CDDP compared to CDDP alone, corresponding to $\sim 20$ fold increase in cell death. The underlying mechanism of chemosensitization is in part associated with USMB-mediated delivery of cisplatin. The combined treatment of USMB+CDDP achieved $25 \pm 6 \mu \mathrm{M}$ intracellular CDDP concentration ( $\sim 8$ fold increase) compared to $3 \mu \mathrm{M}$ with CDDP alone. The efficacy of the combined treatment was dependent on the exposure conditions of USMB and CDDP, and appeared to be independent of the combined treatment order with 48-hour drug-incubation time. Synergistic enhancement of cell death with combined treatment was observed for ICD values less than 6 corresponding to low peak negative pressures and microbubble concentrations (including $230 \mathrm{kPa}+1.7 \% \mathrm{v} / \mathrm{v}$, $580 \mathrm{kPa}+0.8 \% \mathrm{v} / \mathrm{v}$, and $580 \mathrm{kPa}+1.7 \% \mathrm{v} / \mathrm{v})$. Whereas, an additive enhancement was observed for ICDs more than 10 corresponding to higher peak negative pressure and microbubble concentrations.

Correlations were found between cell death and intracellular CDDP concentration with acoustic microbubble activity in terms of integrated cavitation dose (ICD), which increased with acoustic pressure and microbubble concentration. Cells undergo higher biomechanical stress with increasing cavitation doses through micro-streaming and shock-waves causing reversible 
and irreversible bio-effects leading to enhanced uptake of cell impermeant molecules and cell death, respectively $[30,57]$. Thus, relatively lower ICDs induced a synergistic effect with the combined treatment whereas higher ICDs induced an additive effect. In addition, a similar correlation coefficient between cell viability and ICD was observed in other studies using Levovist ${ }^{\circledR}$ microbubble and HeLa cells [38].

The underlying mechanism of the combined treatment was associated with USMBinduced enhancement of CDDP delivery and USMB-induced cell death. Generally, the enhanced intracellular accumulation of molecules with ultrasound and microbubbles has been associated with diffusion through membrane disruption, and enhanced endocytosis and fluid-phase uptake $[8,10,47]$. However, under treatment condition of cells being incubated with CDDP for 48 hours, no statistically significant differences in cell viabilities and intracellular CDDP concentration was observed for the altered treatment orders, suggesting that endocytosis and fluid phase uptake may be mainly responsible for the enhanced intracellular CDDP concentration.

In addition, other biological pathways may have been triggered by USMB such as Bcl-2, an anti-apoptotic protein, which has been shown to suppress apoptosis in human breast cancer cells treated with CDDP by forming a heterodimer with pro-apoptotic protein, Bax [9, 26, 28]. For instance, CDDP treated human breast cancer MCF-7 cells have shown $\sim 4$ fold increase in intracellular CDDP accumulation with CDDP treatment alone [6]; however, despite enhanced CDDP accumulation MCF-7 cells seldom trigger apoptosis due to high expressions of Bcl-2, which is proposed as the mechanism responsible for CDDP resistance in MCF-7 breast cancer cells $[18,23,24]$. In addition, human breast cancer studies on MCF-7 cells has shown to overcome CDDP resistance using Bcl-2 siRNA, which enhances CDDP induced apoptosis by 
reducing the $\mathrm{Bcl}-2 / \mathrm{Bax}$ protein ratio [9]. Interestingly, the application of USMB therapy has also shown to decrease the ratio of Bcl-2/Bax proteins, which can act as CDDP sensitivity regulator for resistive cancers $[13,36]$. Further investigation is required to assess the effect of USMB on Bcl-2/Bax ratio and efficacy of combined treatment with CDDP in breast cancer cells.

\subsection{Conclusion}

Treatment efficacy of cisplatin (CDDP) improved synergistically by the application of ultrasound-microbubble (USMB) therapy in CDDP-resistant human breast cancer cells, MDAMB-231, in part by enhancing intracellular delivery of cisplatin. Combined treatment increased cell death by $\sim 20$ fold and intracellular cisplatin concentration by $\sim 8$ fold. Treatment efficacy of the combined treatment was dependent on ultrasound acoustic pressure, microbubble concentration and CDDP concentration, but independent of treatment order. In addition, treatment efficacy is associated with microbubble cavitation activity. The microbubble integrated cavitation dose (ICD) was correlated with cell death and intracellular CDDP concentration. Combined treatment with relatively lower ICDs induced a synergistic effect on cell death whereas higher ICDs induced an additive effect. Overall, ICD can potentially predict the improved efficacy of CDDP by USMB-mediated intracellular delivery and cell death in human breast cancer cells.

\section{References}

1. Siddik, Z.H., Cisplatin: mode of cytotoxic action and molecular basis of resistance. Oncogene, 2003. 22(47): p. 7265-7279.

2. Luo, T., et al., Electron transfer-based combination therapy of cisplatin with tetramethylp-phenylenediamine for ovarian, cervical, and lung cancers. Proceedings of the National Academy of Sciences of the United States of America, 2012. 109(26): p. 10175-10180. 
3. Galluzzi, L., et al., Molecular mechanisms of cisplatin resistance. Oncogene, 2012. 31(15): p. 1869-1883.

4. Stewart, J.M., et al., Phenotypic heterogeneity and instability of human ovarian tumorinitiating cells. Proceedings of the National Academy of Sciences of the United States of America, 2011. 108(16): p. 6468-6473.

5. Mack, K.M., R.G. Canada, and P.A. Andrews, The effects of terbium on the cellular accumulation of cisplatin in MDA-MB-231 human breast tumor cells. Cancer Chemotherapy and Pharmacology, 1997. 39(3): p. 217-222.

6. Ghezzi, A., et al., Uptake of antitumor platinum(II)-complexes by cancer cells, assayed by inductively coupled plasma mass spectrometry (ICP-MS). Journal of Inorganic Biochemistry, 2004. 98(1): p. 73-78.

7. Bernard, V., et al., Ultrasound and Cisplatin Combined Treatment of Human Melanoma Cells A375-the Study of Sonodynamic Therapy. Ultrasound in Medicine and Biology, 2012. 38(7): p. 1205-1211.

8. Sasaki, N., et al., Activation of Microbubbles by Short-Pulsed Ultrasound Enhances the Cytotoxic Effect of Cis-Diamminedichloroplatinum (Ii) in a Canine Thyroid Adenocarcinoma Cell Line in Vitro. Ultrasound in Medicine and Biology, 2012. 38(1): p. 109-118.

9. Yde, C.W. and O.G. Issinger, Enhancing cisplatin sensitivity in MCF-7 human breast cancer cells by down-regulation of Bcl-2 and cyclin D1. International Journal of Oncology, 2006. 29(6): p. 1397-1404.

10. Heath, C.H., et al., Microbubble Therapy Enhances Anti-tumor Properties of Cisplatin and Cetuximab In Vitro and In Vivo. Otolaryngology-Head and Neck Surgery, 2012. 146(6): p. 938-945.

11. Mo, S., et al., Ultrasound-enhanced drug delivery for cancer. Expert Opin Drug Deliv, 2012. 9(12): p. 1525-38.

12. Honda, H., Q.-L. Zhao, and T. Kondo, Effects of dissolved gases and an echo contrast agent on apoptosis induced by ultrasound and its mechanism via the mitochondriacaspase pathway. Ultrasound in medicine \& biology, 2002. 28(5): p. 673-82.

13. Wu, F., et al., Ultrasound Reverses Multidrug Resistance in Human Cancer Cells by Altering Gene Expression of Abc Transporter Proteins and Bax Protein. Ultrasound in Medicine and Biology, 2011. 37(1): p. 151-159.

14. Ashush, H., et al., Apoptosis induction of human myeloid leukemic cells by ultrasound exposure. Cancer Research, 2000. 60(4): p. 1014-1020.

15. Craig A. Almeida, S.A.B., Cancer: Basic Science and Clinical Aspects. 2010: Wiley, 2010.

16. Stein, A.B.P.G.S., The biology and treatment of cancer: understanding cancer. 2009.

17. Ruvolo, P.P., X. Deng, and W.S. May, Phosphorylation of Bcl2 and regulation of apoptosis. Leukemia, 2001. 15(4): p. 515-22.

18. Haldar, S., et al., Down-Regulation of Bcl-2 by P53 in Breast-Cancer Cells. Cancer Research, 1994. 54(8): p. 2095-2097.

19. Torpy, J.M.L., Cassio; Glass, Richard M, Cancer: The basics. JAMA, 2010.

20. Moros, E., Physics of thermal therapy : fundamentals and clinical applications. Imaging in medical diagnosis and therapy. 2013, Boca Raton, FL: CRC/Taylor \& Francis. xvi, 359 p. 
21. Eckstein, N., Platinum resistance in breast and ovarian cancer cell lines. J Exp Clin Cancer Res, 2011. 30: p. 91.

22. Brown, V.S., T; Symonds, R Paul, Principles of chemotherapy and radiotherapy. Obstetrics, Gynaecology \& Reproductive Medicine, 2011. 21(12).

23. Florea, A.M. and D. Busselberg, Cisplatin as an anti-tumor drug: cellular mechanisms of activity, drug resistance and induced side effects. Cancers (Basel). 3(1): p. 1351-71.

24. Florea, A.M. and D. Busselberg, Cisplatin as an anti-tumor drug: cellular mechanisms of activity, drug resistance and induced side effects. Cancers (Basel), 2011. 3(1): p. 135171.

25. Park, S. and S.J. Lippard, Redox State-Dependent Interaction of HMGB1 and CisplatinModified DNA. Biochemistry, 2011. 50(13): p. 2567-2574.

26. Basu, A. and S. Krishnamurthy, Cellular responses to Cisplatin-induced DNA damage. J Nucleic Acids. 2010.

27. Wang, D. and S.J. Lippard, Cellular processing of platinum anticancer drugs. Nature Reviews Drug Discovery, 2005. 4(4): p. 307-320.

28. Kelland, L.R., Preclinical perspectives on platinum resistance. Drugs, 2000. 59: p. 1-8.

29. Frenkel, V., Therapeutic ultrasound mechanisms to applications. Nova Science Publishers, 2011.

30. Pitt, W.G., G.A. Husseini, and B.J. Staples, Ultrasonic drug delivery--a general review. Expert opinion on drug delivery, 2004. 1(1): p. 37-56.

31. Karshafian, R., et al., Sonoporation by Ultrasound-Activated Microbubble Contrast Agents: Effect of Acoustic Exposure Parameters on Cell Membrane Permeability and Cell Viability. Ultrasound in Medicine and Biology, 2009. 35(5): p. 847-860.

32. Unger, E.C., et al., Local drug and gene delivery through microbubbles. Progress in cardiovascular diseases, 2001. 44(1): p. 45-54.

33. Bao, S., B.D. Thrall, and D.L. Miller, Transfection of a reporter plasmid into cultured cells by sonoporation in vitro. Ultrasound in medicine \& biology, 1997. 23(6): p. 953-9.

34. Iwanaga, K., et al., Local delivery system of cytotoxic agents to tumors by focused sonoporation. Cancer Gene Ther, 2007. 14(4): p. 354-63.

35. Kinoshita and K. Hynynen, Key factors that affect sonoporation efficiency in in vitro settings: The importance of standing wave in sonoporation. Biochem Biophys Res Commun, 2007. 359(4): p. 860-865.

36. Bai, W.K., et al., Treatment of PC-3 cells with ultrasound combined with microbubbles induces distinct alterations in the expression of Bcl-2 and Bax. Chinese Science Bulletin, 2013. 58(28-29): p. 3535-3540.

37. Al-Mahrouki, A.A., et al., Bioeffects of Ultrasound-Stimulated Microbubbles on Endothelial Cells: Gene Expression Changes Associated with Radiation Enhancement in Vitro. Ultrasound in Medicine and Biology, 2012. 38(11): p. 1958-1969.

38. Lai, C.-Y., et al., Quantitative relations of acoustic inertial cavitation with sonoporation and cell viability. Ultrasound in medicine \& biology, 2006. 32(12): p. 1931-41.

39. Chen, W.-S., et al., Inertial cavitation dose and hemolysis produced in vitro with or without Optison. Ultrasound in medicine \& biology, 2003. 29(5): p. 725-37.

40. Karshafian, R., et al. Enhancing chemotherapy by ultrasound and microbubbles: Effect of acousticpressure and treatment order in in vitro suspension of reast and prostate cancercells. in Proceedings - IEEE Ultrasonics Symposium. 
41. Todorova, M., et al., Antitumor effects of combining metronomic chemotherapy with the antivascular action of ultrasound stimulated microbubbles. International Journal of Cancer, 2013. 132(12): p. 2956-2966.

42. Goertz, D.E., et al., Antitumor Effects of Combining Docetaxel (Taxotere) with the Antivascular Action of Ultrasound Stimulated Microbubbles. Plos One, 2012. 7(12).

43. Watanabe, Y., et al., Low-intensity ultrasound and microbubbles enhance the antitumor effect of cisplatin. Cancer Science, 2008. 99(12): p. 2525-2531.

44. Lee, N.G., et al., Sonoporation enhances chemotherapeutic efficacy in retinoblastoma cells in vitro. Invest Ophthalmol Vis Sci, 2011. 52(6): p. 3868-73.

45. Ghoshal, G., S. Swat, and M.L. Oelze, Synergistic effects of ultrasound-activated microbubbles and doxorubicin on short-term survival of mouse mammary tumor cells. Ultrason Imaging, 2012. 34(1): p. 15-22.

46. Wang, A.H., S.; Berry, J.; Murphree, A.; Fawzi, A., Sonoporation Enhances Cisplatin and Topotecan activity against Y79 Retinoblastoma cells In Vitro. Invest Ophthalmol Vis Sci, 2011. 52.

47. Mymryk, J.S., E. Zaniewski, and T.K. Archer, Cisplatin Inhibits Chromatin Remodeling, Transcription Factor-Binding, and Transcription from the Mouse Mammary-Tumor Virus Promoter in-Vivo. Proceedings of the National Academy of Sciences of the United States of America, 1995. 92(6): p. 2076-2080.

48. Jelenc, J., et al., Low-frequency ultrasound in vitro: experimental system and ultrasoundinduced changes of cell morphology. 2013 36th International Convention on Information and Communication Technology, Electronics and Microelectronics (Mipro), 2013: p. 340-344.

49. Bliss, C.I., The toxicity of poisons applied jointly. Annals of Applied Biology, 1939. 26(3): p. 585-615.

50. Shimizu, M. and Rosenber.B, Similar Action to Uv-Irradiation and a Preferential Inhibition of DNA-Synthesis in Escherichia-Coli by Antitumor Platinum Compounds. Journal of Antibiotics, 1973. 26(4): p. 243-245.

51. Harder, H.C., R.G. Smith, and A.F. Leroy, Template Primer Inactivation by CisDichlorodiammine and Trans-Dichlorodiammine Platinum for Human DNA-Polymerase Alpha,Beta, and Rauscher Murine Leukemia-Virus Reverse-Transcriptase, as a Mechanism of Cytotoxicity. Cancer Research, 1976. 36(10): p. 3821-3829.

52. Szabo, T.L., DIAGNOSTIC ULTRASOUND IMAGING: INSIDE OUT. Textbook, 2005.

53. Bandura, D.R., et al., Mass Cytometry: Technique for Real Time Single Cell Multitarget Immunoassay Based on Inductively Coupled Plasma Time-of-Flight Mass Spectrometry. Analytical Chemistry, 2009. 81(16): p. 6813-6822.

54. Chang, Q., et al., Single-cell measurement of the uptake, intratumoral distribution and cell cycle effects of cisplatin using mass cytometry. International Journal of Cancer, 2015. 136(5): p. 1202-1209.

55. Tarapacki, C. and R. Karshafian, Enhancing laser therapy using PEGylated gold nanoparticles combined with ultrasound and microbubbles. Ultrasonics, 2015. 57: p. 3643.

56. Engineering fluorescent proteins.

57. Lawrie, A., et al., Microbubble-enhanced ultrasound for vascular gene delivery. Gene Ther, 2000. 7(23): p. 2023-7. 


\section{Supplementary information}

\section{Intracellular platinum concentration per cell ( $\mu M)$}

Table 2 represents the variables used to calculate the intracellular cisplatin concentration. Equation 3 was used in calculating the number of intracellular cisplatin $(\mathrm{Pt})$ atoms per cell for each treatment condition (including no treatment as background). Each of the variables was obtained from either the tuning solution or gated values from Cytobank analysis of the mass cytometer raw data.

Table 2: Variables used to calculate intracellular cisplatin concentation obtained from either tuning solution or mass cytometer data gating using CytoBank

\begin{tabular}{|c|c|}
\hline $\mathrm{A}=1 \mathrm{~mole}=6.022 \times 1023$ atoms $/$ cell & $\mathrm{Pt}(\mathrm{sum})=\operatorname{sum}[$ mean $(\mathrm{Pt}-194: 196)]$ \\
\hline $\mathrm{V}=$ Volume of a cell is $2 \mathrm{pl}=2 \times 10^{-12} \mathrm{~L} /$ cell & Pt (NA) = sum[natural abundance(Pt194:196)] \\
\hline $\mathrm{Y}(\mathrm{x})=$ platinum atoms $/$ cell for each treatment $(\mathrm{x})$ & Lu $(\mathrm{NA})=\mathrm{Lu}$ with correction for natural abundance \\
\hline $\mathrm{Z}=$ Number of platinum moles per cell & $\mathrm{Lu}=$ number of atoms of Lutetium $(\mathrm{Lu})$ per bead \\
\hline I $($ conc $)=$ Intracellular Cisplatin concentration & $\mathrm{Tm}(\mathrm{avg})=$ average of Thulium $(\mathrm{Tm})$ intensities \\
\hline $\mathrm{C}(\mathrm{Ir})=$ coefficient of iridium & $\mathrm{C}(\mathrm{Tm})=$ coefficient of Thulium \\
\hline $\begin{array}{l}\text { I }(\mathrm{sum})=\text { the sum the average intensities Iridium } \\
(191 \& 193)\end{array}$ & $\begin{array}{l}\mathrm{Y}(\mathrm{x})^{\prime}=\text { platinum atoms/ cell for treatment }(\mathrm{x}) \text { minus } \\
\text { treatment (background) }\end{array}$ \\
\hline
\end{tabular}

$$
Y(x)=\frac{\left[P t(\text { sum }) *\left[\frac{100}{P t(N A)}\right]\right]}{\left[\frac{\frac{I(\text { sum })}{C(I r)}}{\operatorname{Tm(avg)}}\right] C\left[\frac{L u}{\operatorname{C(Tm)}}\right]} *\left[\frac{100}{\operatorname{mean}(L u) *\left(\frac{100}{L u(N A)}\right)}\right]
$$

$\mathrm{Y}$ (background) was subtracted from $\mathrm{Y}$ (treatment) number of atoms per cell; after which $\mathrm{Y}$ is used to calculate intracellular cisplatin concentration. For example, after background subtraction, if $\mathrm{Y}(\mathrm{x})^{\prime}=2.36 \times 10^{7}$ atoms $/$ cell, the intracellular cisplatin concentration would be as follows: 


$$
\begin{gathered}
Z=\frac{Y(x)^{\prime}}{A}=\frac{\left[2.36 * 10^{7} \frac{\mathrm{atoms}}{\mathrm{cell}}\right]}{\left[6.022 * 10^{23} \frac{\mathrm{atoms}}{\mathrm{mol}}\right]}=3.92 \times 10^{-17} \frac{\mathrm{mol}}{\mathrm{cell}} \\
I(\text { conc })=\frac{Z}{V}=\frac{\left[3.92 \times 10^{-17} \frac{\mathrm{mol}}{\mathrm{cell}}\right]}{\left[2 \times 10^{-12} \frac{\mathrm{L}}{\mathrm{cell}}\right]}=19.61 * 10^{-6} \frac{\mathrm{mol}}{\mathrm{L}}=19.61 \mu \mathrm{M}
\end{gathered}
$$

Thus, the intracellular cisplatin concentration per cell is $19.61 \mu \mathrm{M}$ for $2.36 \mathrm{x}^{7}$ atoms of cisplatin per cell.

\section{Cell viability comparison of statistically significant treatment conditions}

Table 3: Summary of non-parametric t-test comparison between CDDP alone and combined USMB+CDDP treatments, where * represents statistically significant conditions

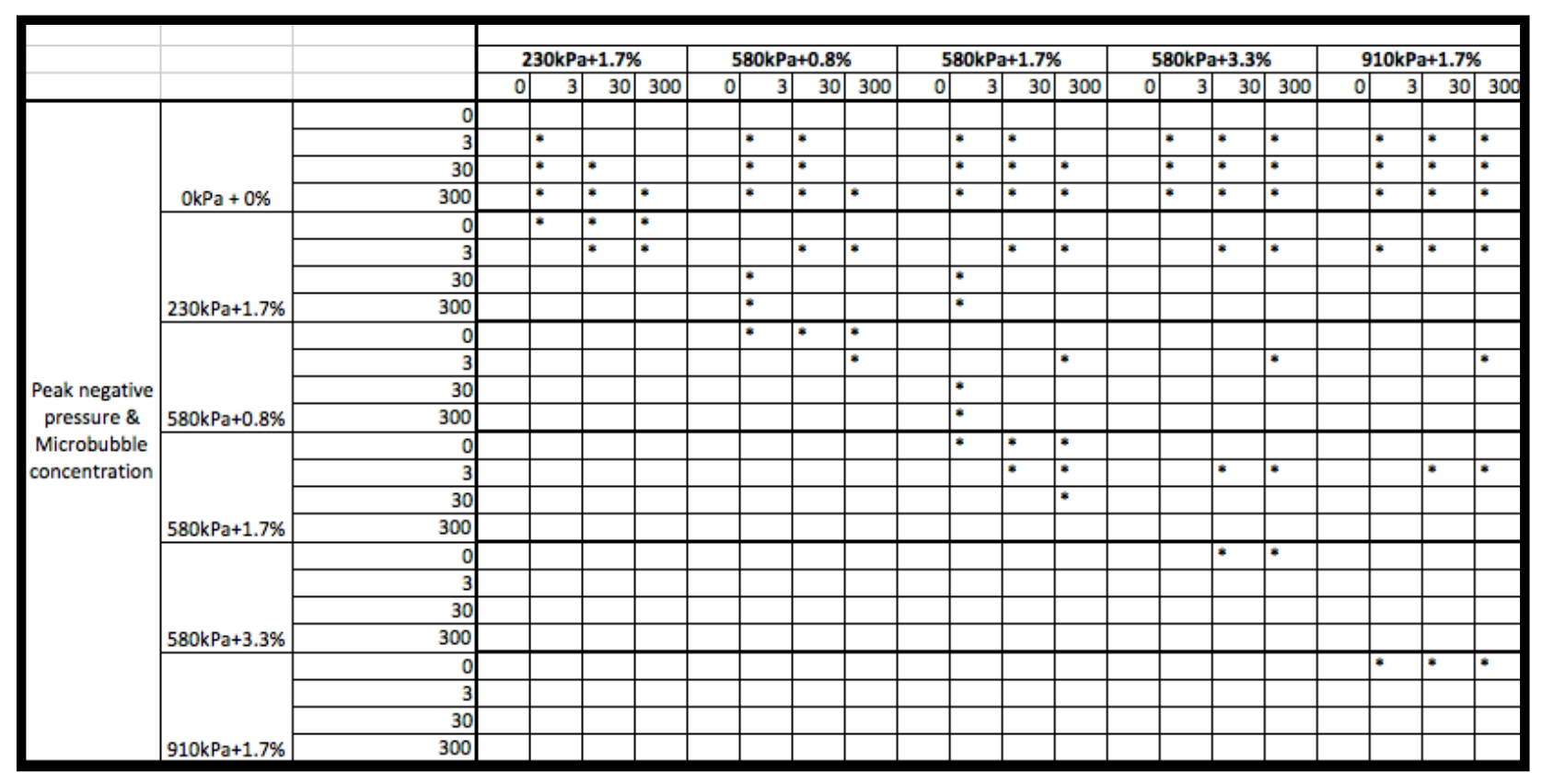




\section{Summary \& Future work}

\subsection{Summary}

This study is guided by the hypothesis that ultrasound-microbubble therapy synergistically enhances cisplatin effectiveness in human breast cancer cells, MDA-MB-231, in part by increasing intracellular cisplatin concentration.

In the study MDA-MB-231 cells in suspension were exposed to CDDP at 4 different concentrations: $0 \mu \mathrm{M}, 3 \mu \mathrm{M}, 30 \mu \mathrm{M}$, and $300 \mu \mathrm{M}$, ultrasound at $500 \mathrm{kHz}$ pulsed-centered frequency with 4 different peak negative pressures: $0 \mathrm{kPa}, 230 \mathrm{kPa}, 580 \mathrm{kPa}$, and $910 \mathrm{kPa}$; and 3 microbubble concentrations: $0.8 \% \mathrm{v} / \mathrm{v}, 1.7 \% \mathrm{v} / \mathrm{v}$, and $3.3 \% \mathrm{v} / \mathrm{v}$. Treatment order with CDDP and USMB therapy was altered to identify combined treatment effectiveness. Cell viability was measured using MTT assay and intracellular CDDP concentration was measured using mass cytometer, after cells were incubated for 48-hours.

Synergistic decrease in cell viability was shown with combined treatment of USMB and CDDP compared to CDDP alone. Synergism was observed at peak negative pressures and microbubble concentrations of $230 \mathrm{kPa}+1.7 \% \mathrm{v} / \mathrm{v}, 580 \mathrm{kPa}+0.8 \% \mathrm{v} / \mathrm{v}$, and $580 \mathrm{kPa}+1.7 \% \mathrm{v} / \mathrm{v}$. The remaining combined treatment conditions $(580 \mathrm{kPa}+3.3 \% \mathrm{v} / \mathrm{v}$ and $910 \mathrm{kPa}+1.7 \% \mathrm{v} / \mathrm{v})$ demonstrated an additive effect on cell viability compared to CDDP treatment alone. Treatment order for all combined treatments had no significant difference.

Significantly higher intracellular CDDP concentration was observed with combined treatment compared to CDDP alone. As peak negative pressure and microbubble (MB) concentrations increased, an increase in intracellular CDDP concentration was observed for combined treatment. Integrated cavitation dose (ICD) increased with increasing peak negative pressures and MB concentrations. Statistical correlation tests observed strong correlation 
between cell death, integrated cavitation dose, and intracellular platinum concentration; thus, indicating amount of cell death is directly correlated with the amount of intracellular CDDP accumulation for all treatment conditions.

The findings in this study support the hypothesis that combined treatment of CDDP with USMB therapy enhances CDDP therapeutic effectiveness in vitro MDA-MB-231 cells compared to CDDP treatment alone. Overall, ICD can potentially predict the improved efficacy of CDDP by USMB-mediated intracellular delivery and cell death in human breast cancer cells.

\subsection{Future work}

This study investigates the understanding of how USMB therapy enhances CDDP therapeutic effectiveness. Although the combined treatment demonstrates enhanced cell death and intracellular CDDP concentration, specific biological effects induced by combined treatment were not examined. Some of these biological effects include pathways activated for enhanced endocytosis and exocytosis of CDDP, and protein expressions of Bcl-2 and Bax. Measuring Bcl2/Bax expression ratios from different combinations of USMB+CDDP will assist the understanding of CDDP's apoptotic response to resistive cell lines. Likewise, it is also just as important to understand the role of endocytosis and exocytosis on intracellular CDDP delivery, post-USMB treatment, which can provide a deeper understanding of the mechanisms involved in the different treatment orders (such as fluid-phase uptake and membrane disruption) investigated in this study. 